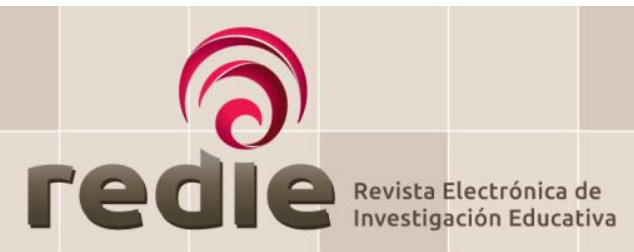

ISSN: $1607-4041$

https://redie.uabc.mx

Vol. 23, 2021/e28

\title{
Estrategias metacognitivas en entornos digitales para estudiantes con baja comprensión lectora
}

\section{Metacognitive Strategies in Digital Environments for Students with Poor Reading Comprehension}

Pedro Félix Novoa-Castillo (1) https://orcid.org/0000-0003-2186-7458

Yrene Cecilia Uribe-Hernández (2) htttps://orcid.org/0000-0001-5893-9262

Luzmila Lourdes Garro-Aburto (3) https://orcid.org/0000-0002-9453-9810

Rosalinn Francisca Cancino-Verde (4) https://orcid.org/0000-0003-0249-5345

(1) Universidad Nacional Mayor de San Marcos

(2) Universidad Nacional de Cañete

(3) Universidad César Vallejo

(4) Universidad Nacional Federico Villarreal

(Recibido: 11 de marzo de 2020; Aceptado para su publicación: 23 de julio de 2020)

Cómo citar: Novoa-Castillo, P. F., Uribe-Hernández, Y. C., Garro-Aburto, L. L. y Cancino-Verde, R. F. (2021). Estrategias metacognitivas en entornos digitales para estudiantes con baja comprensión lectora. Revista Electrónica de Investigación Educativa, 23, e28, 1-34. https://doi.org/10.24320/redie.2021.23.e28.3953

\section{Resumen}

La investigación buscó establecer la incidencia que tienen las estrategias metacognitivas en entornos digitales en 85 estudiantes de 10 a 13 años que obtuvieron bajos niveles de comprensión lectora en las Pruebas PISA de 2018. Se conformó un Grupo Control (52 participantes) y un Grupo Experimental (53), y sólo con el Experimental se trabajó durante un semestre académico con las estrategias metacognitivas en entornos digitales (basadas en la Escala de conciencia lectora ESCOLA). Los resultados arrojaron diferencias significativas entre ambos grupos, a favor del grupo Experimental, demostrando que las estrategias metacognitivas en entornos digitales mejoran significativamente la comprensión lectora.

Palabras clave: comprensión, lectura, entorno educacional, estrategias educativas

\section{Abstract}

This research attempts to determine the impact of metacognitive strategies in digital environments among 85 students, aged 10 to 13 years, who obtained poor reading comprehension scores in the 2018 PISA tests. A control group (52 participants) and experimental group (53 participants) were formed, and for one academic semester, only the experimental group worked on metacognitive strategies in digital environments (based on the reading awareness scale ESCOLA). The results showed significant differences between the two groups, in favor of the experimental group, indicating that metacognitive strategies in digital environments significantly improve reading comprehension.

Keywords: comprehension, reading, learning environment, educational strategies 


\section{Introducción}

\subsection{Estrategias metacognitivas}

Debido a los problemas de comprensión lectora manifestados por los estudiantes escolares de Latinoamérica en las últimas evaluaciones internacionales (PISA, entre otras) y corroborado por varios estudios (González, 2018; González-López, 2019; Grimaldo, 1998; Morales, 2011; Mujica et al., 2011 y Vílchez, 2003), los investigadores han propuesto diversas alternativas de solución. Una de ellas ha sido optar por las estrategias metacognitivas (Correa et al., 2018; Fonseca et al., 2018; Martínez y Caballero, 2019; Noriega, 2018; Rueda y Gutiérrez, 2019); estos trabajos remarcan la necesidad de establecer mecanismos didácticos que permitan no sólo la comprensión, sino la reflexión de dicha comprensión.

Según Flavell (1976), la metacognición se refiere: "Al control activo y a la consecuente regulación y orquestación de los procesos en relación con los objetos de conocimiento a los que se refieren, normalmente al servicio de alguna meta concreta u objetivo" (p. 12).

El proceso metacognitivo se vuelve imprescindible, en especial, para los estudiantes que presentan problemas de aprendizaje o bajo rendimiento (González-López, 2019; Graham et al., 2005). La metacognición permite la autorregulación en procesos de orden superior como la percepción, la atención y la memoria. Mecanismos cognitivos que se activan cuando el ser humano se encuentra aprendiendo, razonando, resolviendo un problema o comprendiendo un texto (Cantillo et al., 2014) (ver Figura 1).

Figura 1. Componentes del conocimiento metacognitvo

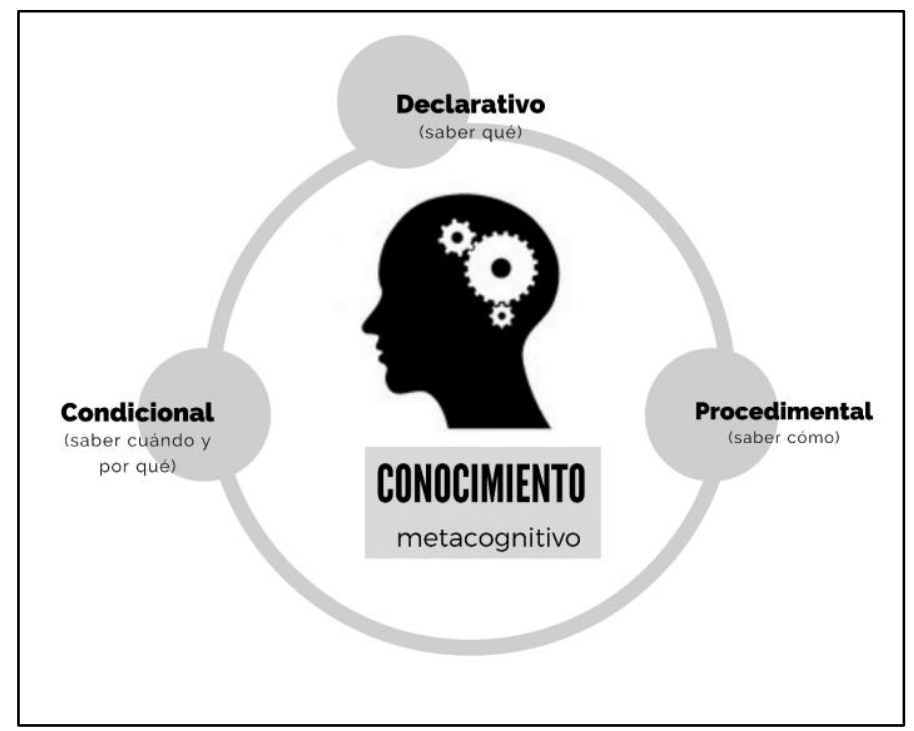

Nota. Basado en Mengual (2017).

En el caso específico de la lectura, los lectores que ejercitan la metacognición son más conscientes de su proceso de comprensión lectora y por tanto tendrán mejores resultados en sus evaluaciones, ya que adquirirán competencias más ágiles y efectivas (Jacobs y Paris, 1987).

Debido a que las estrategias no se dan de manera espontánea, sino que requieren de una planificación, desarrollo y evaluación por parte del docente (Solé, 2005), conviene plantear diversos diseños de estrategias que involucren lo didáctico, lo tecnológico y lo metacognitivo además del logro de aprendizaje específico.

Dentro del gran repertorio de estrategias metacognitivas para la comprensión lectora, conviene definir un tipo en específico. Según Morles (1991) existen: 1) estrategias de organización empleadas para que el lector a partir de operaciones mentales reorganice la información obtenida en la lectura y la disponga de 
manera visual y resumida de la forma más significativa y conveniente para él; 2) estrategias de elaboración aplicadas con la finalidad de crear nuevo conocimiento relacionado con lo leído y asegurar así la comprensión, a través de la formulación de inferencias e hipótesis; 3) estrategias de focalización que se concentran en los temas más relevantes; 4) estrategias de integración donde se articula de manera progresiva y coherente la información que se va obteniendo durante la lectura; 5) estrategias de verificación que se circunscriben a corroborar la interpretación o predicción del lector antes de leer con lo que finalmente leyó.

Para la presente investigación se emplearon los entornos de aprendizaje de las plataformas: miMind (organización, focalización, integración y elaboración), Educaplay (elaboración) y Kahoot y Google Form (verificación). Este empleo de plataformas sirvió para que la reflexión metacognitiva sea explícita, con reiteración de las preguntas basadas en el test ESCOLA (que se detallarán posteriormente). Y así asegurar la orientación más idónea en cada componente metacognitivo: planificación, supervisión y evaluación de cómo comprendemos, cómo lo estamos haciendo y cómo podríamos mejorar. De tal forma que la consciencia metacognitiva se presenta explícitamente relacionada al mejoramiento sostenido de la comprensión. Lo explícito deriva en una mejora no sólo de la comprensión, sino también del uso de la información y el acercamiento a lo tecnológico (Ministerio de Educación, 2018).

Una vez terminadas las actividades, se pasó al último nivel que es el proceso metacognitivo implícito, donde los estudiantes eran evaluados mediante una lista de cotejo, pero sin pedir ninguna reflexión metacognitiva antes, durante ni después de la lectura. Es en esta última etapa o nivel de metacomprensión que resaltarán los logros en los estudiantes de baja comprensión, asumiendo que ya han internalizado los procesos metacogntivos y estos se realizan de manera casi automática (Figura 2). Una vez comprobado esto, se evalúa el postest para corroborar los avances comprensivos.

Figura 2. Componentes del proceso metacognitivo en la comprensión lectora

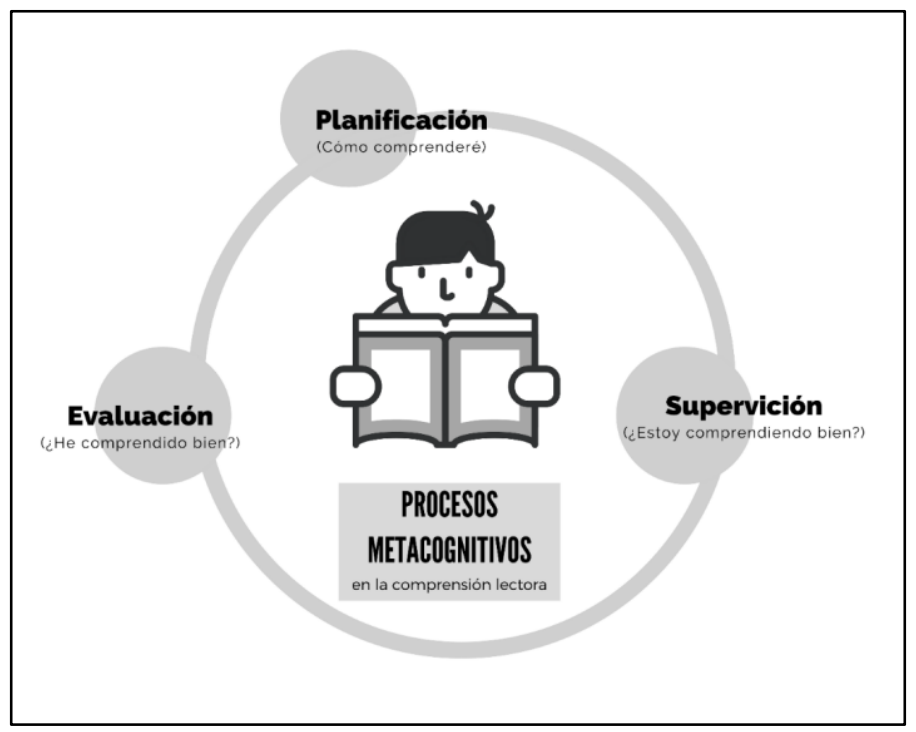

\subsection{Competencia lectora}

La competencia lectora involucra una serie de destrezas cognitivo-lingüísticas que van desde el proceso básico de decodificar hasta el bagaje de saberes, léxico, esquemas textuales y mentales para dar paso a la comprensión (incluyendo lo leído) a la concepción del mundo. La competencia lectora, además, activa complejas y permanentes habilidades de cognición: como la autorregulación, la autorreflexión y la capacidad de optar por diversas estrategias cuando comprende un texto de manera activa y por múltiples intenciones (Cáceres et al., 2018) (ver Figura 3). 
Figura 3. Proceso de la comprensión lectora

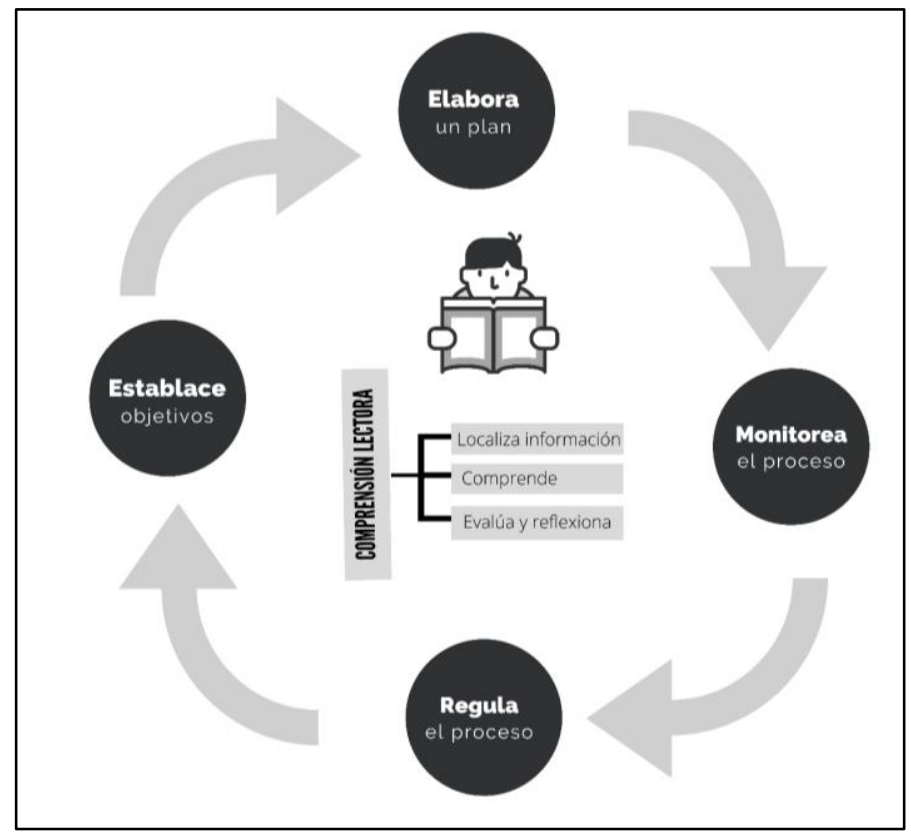

Nota. Basado en Cáceres et al. (2018).

Un recurso válido para el control del proceso metacognitivo es la retroalimentación y la autorregulación mediada por los entornos y las facilidades de interacción y multimedios de las TIC, así como estar siempre consciente de las estrategias metacognitivas empleadas (Ministerio de Educación, 2018). La combinación de todo ello arroja un buen o bajo nivel de comprensión.

Esta investigación tomó en cuenta los niveles que plantearon las Pruebas PISA (2018): Nivel 6 (a partir del puntaje 698); Nivel 5 (puntaje 624-697); Nivel 4(puntaje 553-623); Nivel 3(puntaje 480-552); Nivel 2(puntaje 407-479); Nivel 1a (puntaje 335-406); Nivel 1b (262-334).

Estos niveles califican los procesos cognitivos de los alumnos al leer fluidamente, al acceder y recuperar información de una lectura, al buscar y seleccionar temas principales, al representar significados literales, al integrar e inferir, al evaluar la calidad y credibilidad de lo leído, al reflexionar sobre el fondo y forma y al detectar y manejar conflictos (Gracida, 2012; PISA, 2018). La investigación optó por sintetizar los procesos cognitivos en Comprensión textual (acceder y recuperar información como identificación de temáticas o personajes, reconocimiento de ambientes, ordenamiento de sucesos, entre otros), Comprensión inferencial (integrar e inferir información a partir de la deducción de hechos posibles, consecuencias no explícitas en el texto, o subtemas entre líneas dentro de la lectura), y Comprensión criterial o crítico valorativa ( al juzgar con argumentos válidos aspectos de la lectura, conducta de personajes, o calificaciones cualitativas de la obra o del estilo de la misma).

Lo contradictorio es que el promedio OCDE en las últimas pruebas PISA (2018) es de 487 (inicios del nivel 3), y el Perú, país donde se realizó la investigación, es de 401 (inicios del nivel 2). Por este motivo, en los grupos elegidos casi no se tuvo que excluir a ningún participante, pues casi todos estaban debajo del nivel 2 o a inicios de éste (a excepción de tres participantes) (Figura 4). 
Figura 4. Niveles de comprensión

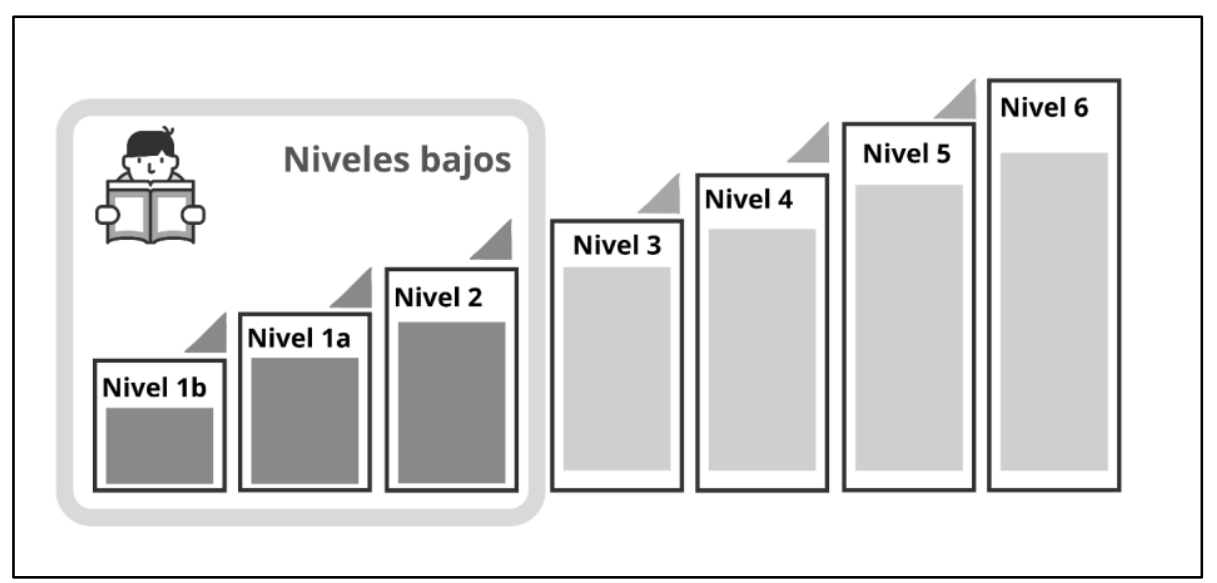

\subsection{Entornos virtuales de aprendizaje}

Los entornos virtuales de aprendizaje están pensados para facilitar el proceso de adquisición y asimilación de conocimientos, de forma paralela al desarrollo de competencias tanto digitales como comprensivas, productivas y reproductivas que estimulen las potencialidades de los estudiantes. Para ello, estos entornos o plataformas emplean recursos digitales como hipervínculos, interacciones, plantillas, correctores inteligentes y demás, para facilitar y agilizar los procesos.

En los últimos años estos entornos son cada vez más cotidianos y requeridos en la comunidad (Borja et al., 2019; Carrillo et al., 2019), sin embargo, es importante que sean incorporados en el quehacer educativo, ya que podrían correr el riesgo de aumentar un vasto contenedor de herramientas tecnológicas y virtuales sin asidero real en lo educativo (Hechavarría et al., 2019). Por tanto, es indispensable que el docente emplee estos entornos, ya que además de agilizar los procesos cognitivos y metacognitivos, logrará acortar distancias emocionales, cognitivas y espaciales (Morado y Ocampo, 2019), tomando en cuenta las grandes brechas socioeconómicas aún insalvables en la mayoría de las sociedades. Los entornos virtuales tienen gran aceptación por parte de los estudiantes (Tapia-Repetto et al., 2019) tanto por temas generacionales, como por la compatibilidad con competencias digitales generales.

Desde que se acuñó el término metacognición (Flavell, 1979), la noción se basa en procesos mentales específicos como la consciencia de la propia consciencia, y el control y regulación de esa consciencia (Arellano, 2019). La relación de la metacognición con los entornos digitales es alta y permite su desarrollo sostenido (Vega, 2019). Esto explica el gran empleo pedagógico en el desarrollo de diversas habilidades que pasen por lo metacognitivo como el desarrollo de habilidades auditivo-musicales (Cubillos, 2019). A causa de esto, para el desarrollo de logros específicos y complejos como la comprensión lectora en jóvenes con una comprensión baja o muy baja, las estrategias metacognitivas serán no sólo un aliado, sino la herramienta indispensable para lograr habilidades procedimentales, conceptuales y actitudinales en la comprensión de un texto.

\subsection{Estrategias metacognitivas en entornos digitales para la comprensión lectora}

Martínez et al. (2019) emplearon entornos digitales desde el e-learning como estrategias didácticas para mejorar la comprensión lectora de textos expositivos, donde la memoria de trabajo fue decisiva para los buenos resultados finales de la experimentación. Se emplearon materiales tecnológicos directamente enfocados a los procesos metacognitivos, como el hecho de emplear discos compactos de lectura que incluían actividades breves que a través de preguntas simples buscar activar el proceso metacognitivo de los lectores. 
Cabero et al. (2018) ofrecieron una herramienta digital para el aumento de estrategias metacognitivas y así mejorar la comprensión lectora de alumnos con dificultades en la lectura. La experimentación demostró la significatividad que tiene la conjunción de estrategia metacognitiva con el entorno digital en favor de niños con dificultades en la lectura.

Martínez et al. (2018) implementaron estrategias didácticas que influenciaron positivamente la comprensión lectora y en las escrituras mediadas por recursos tecnológicos. Estos hallazgos experimentales se corroboran con los trabajos correlacionales entre las estrategias metacognitivas y los niveles de comprensión lectora (Chipana, 2018; Mogrovejo, 2019; Rosales, 2018). Y la búsqueda permanente de la independencia del lector gracias a esa relación entre desempeño lector y estrategia metacognitiva según lo demostraron Artel et al., Brown, Cantrell et al. y Palincsar et al. (como se citó en Ministerio de Educación, 2018, p. 49).

Es así como la comunidad docente implementa estrategias para mejorar la comprensión lectora relacionándola con las TIC y los entornos digitales (Ayala et al., 2017; Lozano, 2018; Meana, 2018; Patiño, 2018; Tapia, 2019). Todas las estrategias se dan de manera explícita para activar la metacomprensión como en Alcas et al. (2019) o el control metacognitivo en Fonseca et al. (2019), trabajos recientes que remarcan lo sustantivo de una orientación didáctica que apele a la consciencia metacognitiva al momento de comprender un texto.

Tomando en cuenta estos antecedentes, el presente trabajo abordó una estrategia metacognitiva a través de entornos virtuales para mejorar la comprensión lectora en un grupo vulnerable: los estudiantes con resultados bajos en las últimas pruebas PISA.

\section{Método}

El trabajo se circunscribirse dentro del paradigma neopositivista (Bendassolli et al., 2010) entendiéndolo como el modelo que involucra la ciencia como el generador de conocimiento. Asimismo, y en consonancia con este paradigma, se optó por el enfoque cuantitativo (Vega-Malagón et al., 2014). Se empleó, a su vez, el método hipotético deductivo (Klimovsky, 1971). El diseño fue cuasi experimental, aplicado, y el corte temporal fue transversal (Morales, 2010), ya que la comprensión lectora se midió en dos momentos específicos (pre y post test).

La población estuvo conformada por 108 estudiantes de cinco colegios de la zona urbano-marginal de Lima (Cono Norte), con edades comprendidas entre 10 a 13 años. Se tomó una muestra de 85 participantes a través del muestreo probabilístico aleatorio simple (Malhotra, 2008). La cantidad se calculó tomando en cuenta el 5\% de margen de error y el 95 \% de confiabilidad (según fórmula de la Figura5). El criterio de inclusión determinante es haber obtenido bajos niveles de comprensión lectora en las Pruebas PISA (2018); y el criterio de exclusión fue el haber llegado a niveles regulares o altos de la mencionada prueba. A través de la muestra de casos aleatorios al 5\% del software SPSS se conformaron dos grupos: uno de Control (52) y otro Experimental (53). 
Figura 5. Fórmula de cálculo de la muestra ${ }^{1}$

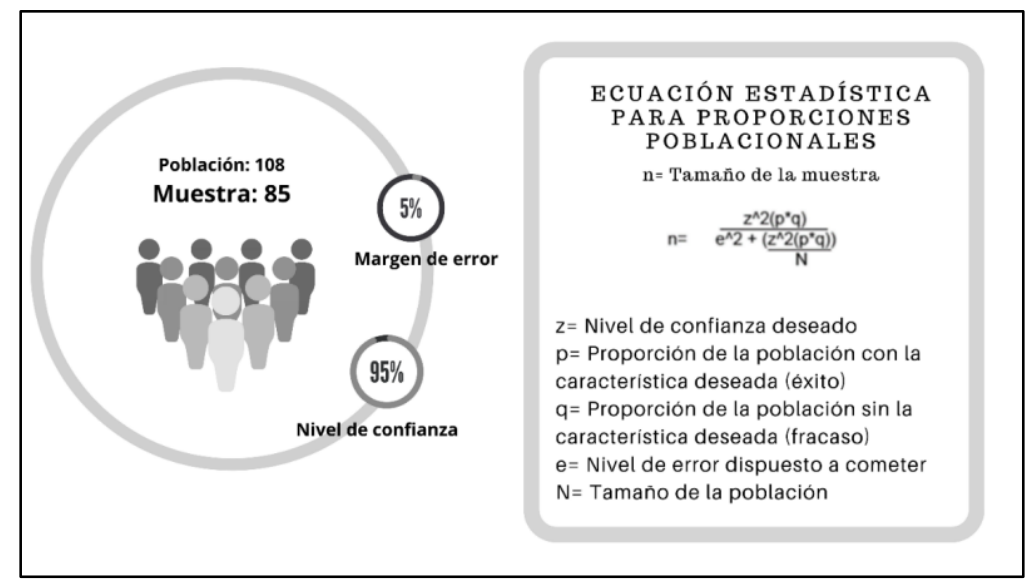

Se emplearon Mapas Mentales Armónicos (MMA) diseñados en la plataforma digital miMind (organización, focalización, integración y elaboración), donde se ofrecieron ejercicios de pre llenado (Anexo 1), para que los alumnos completaran la información requerida y se familiarizaran con el seguimiento de su proceso metacomprensivo. Se utilizaron recursos didácticos de Educaplay (elaboración), y Thatquiz, Kahoot (verificación).

Los materiales se elaboraron tomando como referencia la Escala de metacomprensión lectora (ESCOLA) de Puente et al. (2009) (Anexo 1). El ESCOLA es una prueba pensada para la medición del procesamiento metacognitivo durante la comprensión lectora; está dirigida a participantes de habla española entre los 8 y 13 años. Este instrumento brinda valiosa información sobre los estudiantes con problemas de comprensión debido a una deficiente o precaria metacognición en los componentes de planificación, supervisión y evaluación. Para esta investigación se empleó el ESCOLA 28, versión breve (la mitad de los ítems de la versión completa de 36 preguntas). Esta versión cuenta con un índice de 0.81 de a de Cronbach, indicador de alta confiabilidad hallado en una población escolar de España (Figura 6).

La investigación empleó en un primer momento los MMA diseñados en el entorno digital miMind para sintetizar de manera esquemática la propuesta metacognitiva de la Prueba ESCOLA 28-A. Se elaboraron 4 MMA metacognitivos de prellenado (Anexo 1), que los alumnos completaron de acuerdo con sus peculiaridades metacognitivas (Anexo 3).

Figura 6. MMA Metacognitivo 01 con base en 4 ítems del Test ESCOLA 28-A

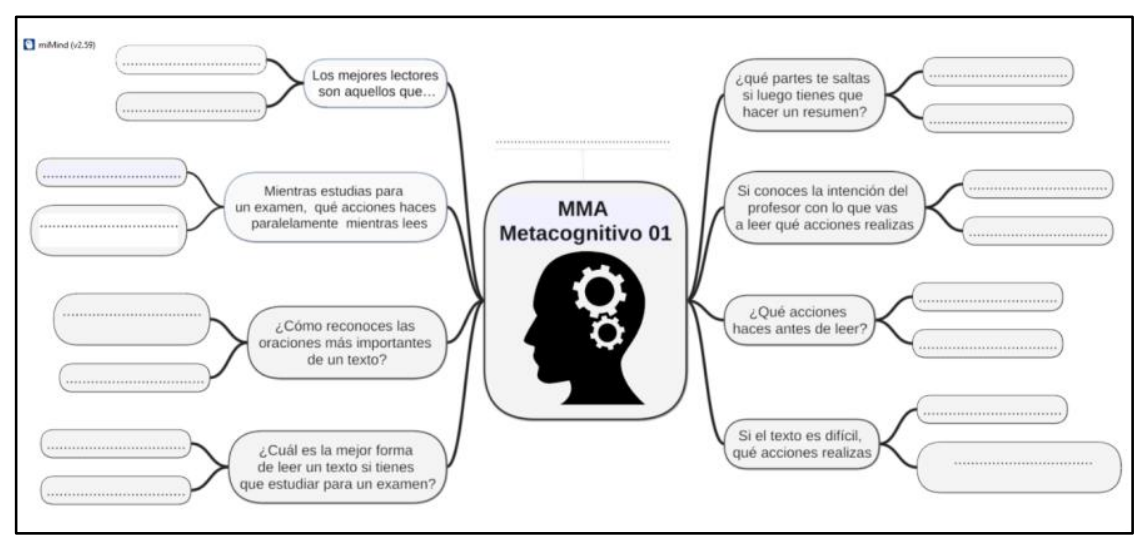

${ }^{1}$ Disponible en http://www.corporacionaem.com/tools/calc muestras.php 
Los MMA son organizadores visuales de información de fuerte impacto cognitivo. Se consideran una variante mejorada de los clásicos Mapas Mentales de Buzán (Novoa et al., 2018). Ya que al comprobarse que en su trazado a mano resultaban muy abigarrados, por lo general sólo eran entendidos por quienes lo hacía. Sin embargo, esto cambió con la incursión de las TIC, ya que muchos programas y aplicativos han armonizado su diseño, haciendo más simétrica la distribución de formas y ramas, convirtiéndose en un importante recurso educativo para la organización y procesamiento de ideas, planes y procesos. En la presente investigación se han empleado los MMA asistidos por computadora, donde el docente facilita esquemas prellenados que, basados en la prueba ESCOLA, van desarrollando contenidos y reflexiones metacognitivas en el estudiante. Asimismo, estos MMA prellenados son adaptados libremente por los participantes, a los que pueden agregar un título relacionado con la lectura, editar imágenes, colores y responder a algunas preguntas sobre su metacomprensión lectora.

En un segundo momento se elaboraron crucigramas y sopa de letras en el entorno Educaplay (elaboración) que reforzaron las ideas de metacognición. Posteriormente, se emplearon cuestionarios en Kahoot y Google Form. En el primero se trabajó con seis ítems de la prueba ESCOLA a manera de familiarización, y luego, en Google Form con los 28 ítems de la prueba (figuras 7 y 8).

Figura 7. Crucigrama en Educaplay²

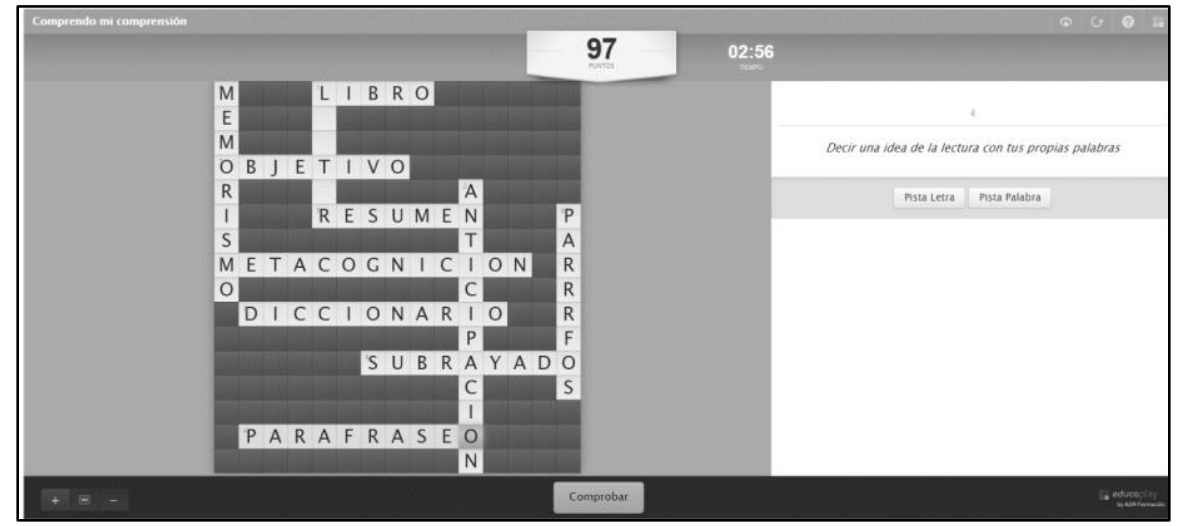

Figura 8. Pregunta metacognitiva en Kahoot con base en 6 ítems del Test ESCOLA 28-A

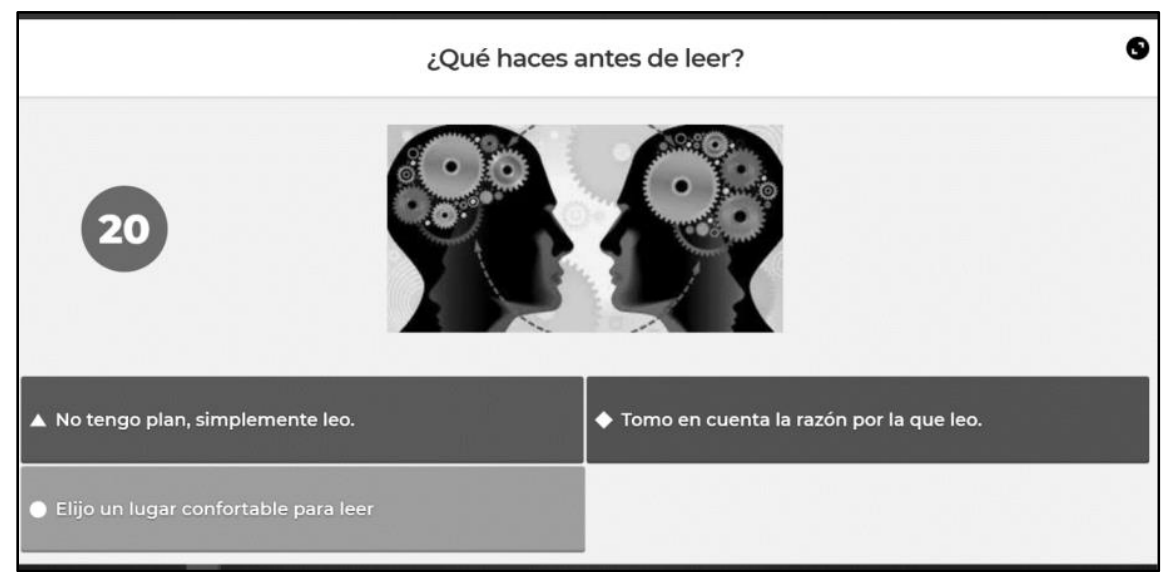

${ }^{2}$ Crucigrama https://es.educaplay.com/recursos-educativos/6205911-comprendo mi comprension.html

3 ítems completos en el Anexo 2. 
Figura 9. Cuestionario metacognitivo basado en el Test ESCOLA 28-A

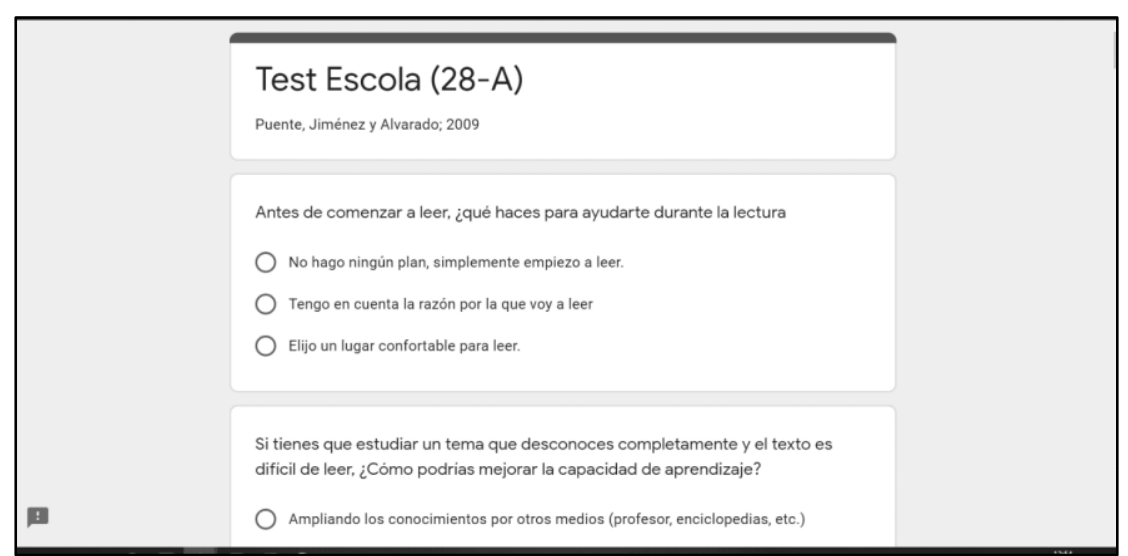

Nota. Puente et al. (2009).

Es importante añadir que luego de las seis preguntas en Kahoot se empleó el formulario Google con todas las preguntas basadas en el Test ESCOLA, así se consolidó el proceso metacognitivo.

Tanto para el pretest como para el postest se tomaron 5 lecturas liberadas de las Pruebas PISA 20095: "Cómo cepillarse los dientes", "El teatro es lo que importa", "El teletrabajo", "El globo", "La seguridad de los teléfonos celulares" (4 preguntas por cada texto, que tomaron un tiempo aproximado de 10 a 15 minutos por lectura). ${ }^{6}$

\section{Resultados}

Aplicada la prueba de normalidad a las notas de Comprensión de textos, se observó que su distribución era no normal ( $p$ valor menor que .005). Por ello, se estableció como prueba no paramétrica para la contrastación de hipótesis la U the Mann Whitney.

Tabla 1. Prueba de normalidad de Comprensión lectora

\begin{tabular}{llccc}
\hline & \multicolumn{3}{c}{ Kolmogorov-Smirnov } & \\
\cline { 2 - 5 } & \multicolumn{1}{c}{ Test } & Estadístico & gl & Sig. \\
\hline Comprensión textual & Pre control & .356 & 52 & .000 \\
& Pre experimental & .301 & 53 & .000 \\
& Pos control & .310 & 52 & .000 \\
& Pos experimental & .288 & 53 & .000 \\
\hline Comprensión inferencial & Pre control & .375 & 52 & .000 \\
& Pre experimental & .272 & 53 & .000 \\
& Pos control & .318 & 52 & .000 \\
& Pos experimental & .298 & 53 & .000 \\
\hline Comprensión criterial & Pre control & .379 & 52 & .000 \\
& Pre experimental & .272 & 53 & .000 \\
& Pos control & .318 & 52 & .000 \\
& Pos experimental & .303 & 53 & .000 \\
\hline Comprensión lectora & Pre control & .339 & 52 & .000 \\
& Pre experimental & .284 & 53 & .000 \\
& Pos control & .272 & 52 & .000 \\
& Pos experimental & .296 & 53 & .000 \\
\hline
\end{tabular}

\footnotetext{
${ }^{4}$ https://Forms.gle/KSUFpcPCrGQ9zC2QA

5 http://www.mecd.gob.es/dctm/inee/recursos/ejemplospruebaspisa.pdf?documentld=0901e72b816484b9

6 https://drive.google.com/open?id=13ws7FHW7hOSfnU2hk18HhV55PZrQoszi
} 


\subsection{Resultados descriptivos}

Se observa en la Figura 10 que en el pretest de Comprensión lectora tanto el grupo control como el grupo experimental estuvieron en condiciones similares, aunque con pequeñas diferencias. En cambio, en el postest estas diferencias se remarcaron en favor del grupo experimental; ya que un importante porcentaje del nivel bajo ascendió al nivel medio; así como otro gran porcentaje se elevó del medio al nivel superior.

Figura 10. Resultado de las Pruebas de Comprensión lectora

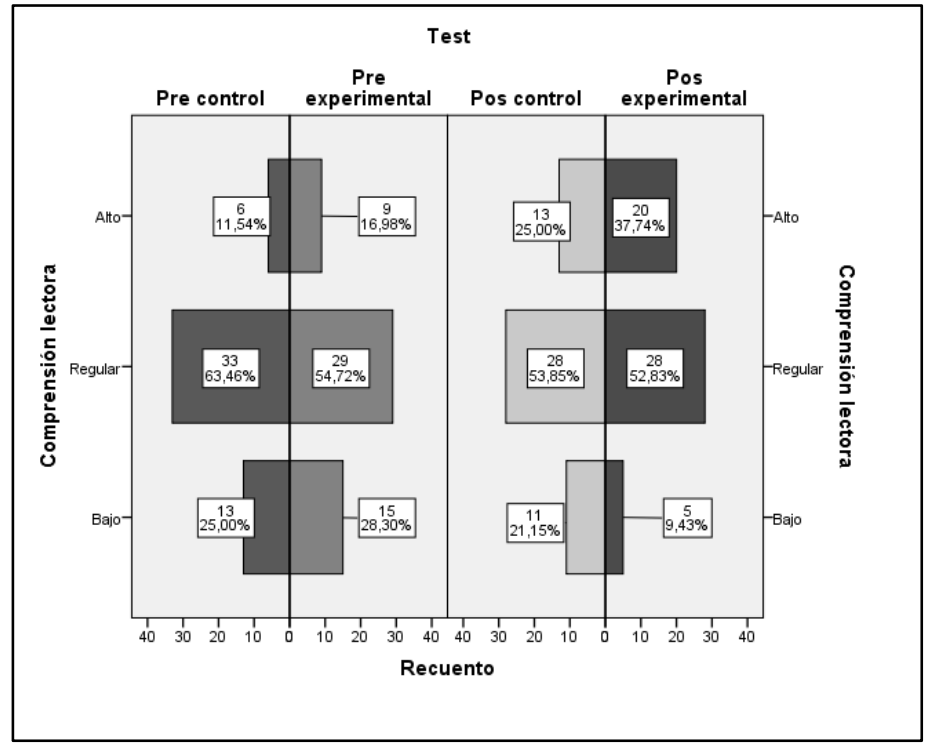

En la Figura 11 se observa que la dimensión Comprensión textual muestra en el pretest ligeras diferencias en los niveles bajo y superior. Mientras que en el postest hay una marcada diferencia en favor del grupo Experimental.

Figura 11. Resultado de las Pruebas de Comprensión textual por pruebas

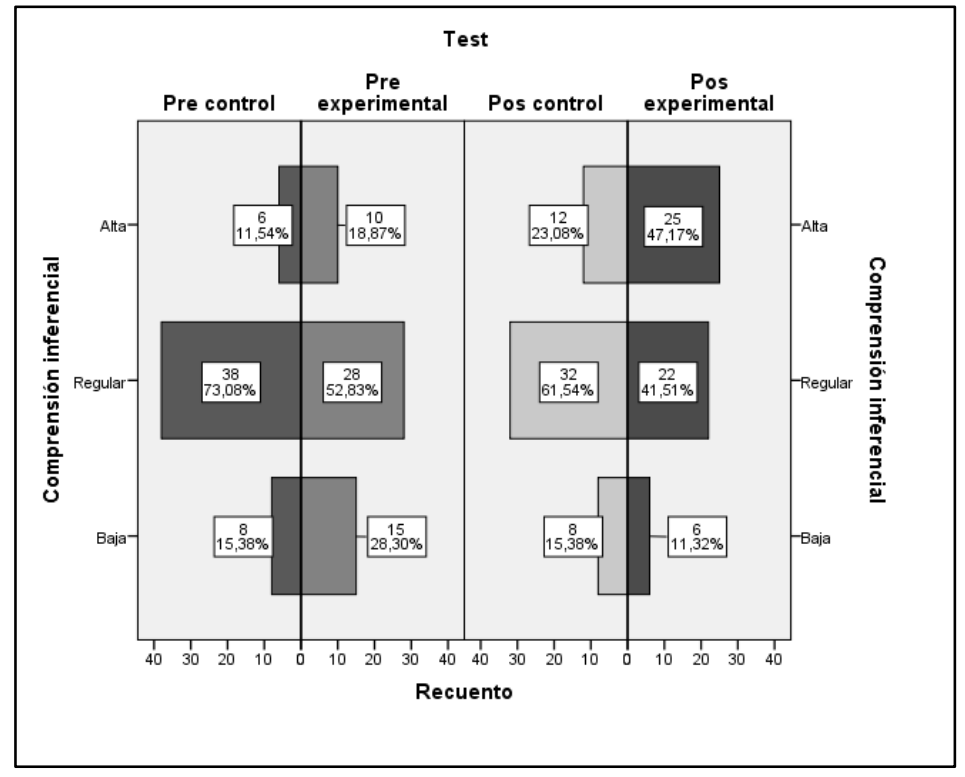


En la Figura 12 se observa que la dimensión Comprensión inferencial muestra en el pretest ligeras diferencias en los niveles bajo, medio y superior. Mientras que en el postest, hay una marcada diferencia en favor del grupo Experimental en el nivel superior, pero ninguna en el nivel bajo y más bien una gran ventaja del Grupo de control en el nivel medio.

Figura 12. Comprensión inferencial por pruebas

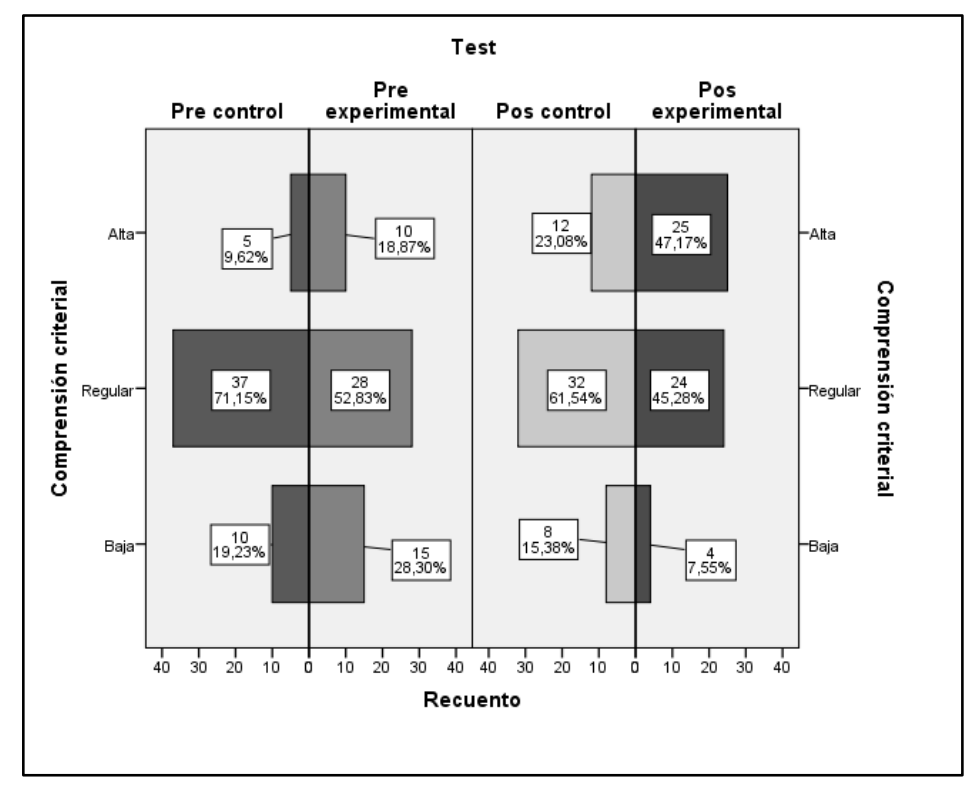

En la figura 13 se observa que la dimensión Comprensión criterial muestra en el pretest ligeras diferencias en los niveles bajo, medio y superior. Mientras que en el postest, hay una marcada diferencia en favor del grupo Experimental en el nivel superior; mas no en el nivel regular donde el Grupo control tiene predominancia.

Figura 13. Comprensión criterial por pruebas

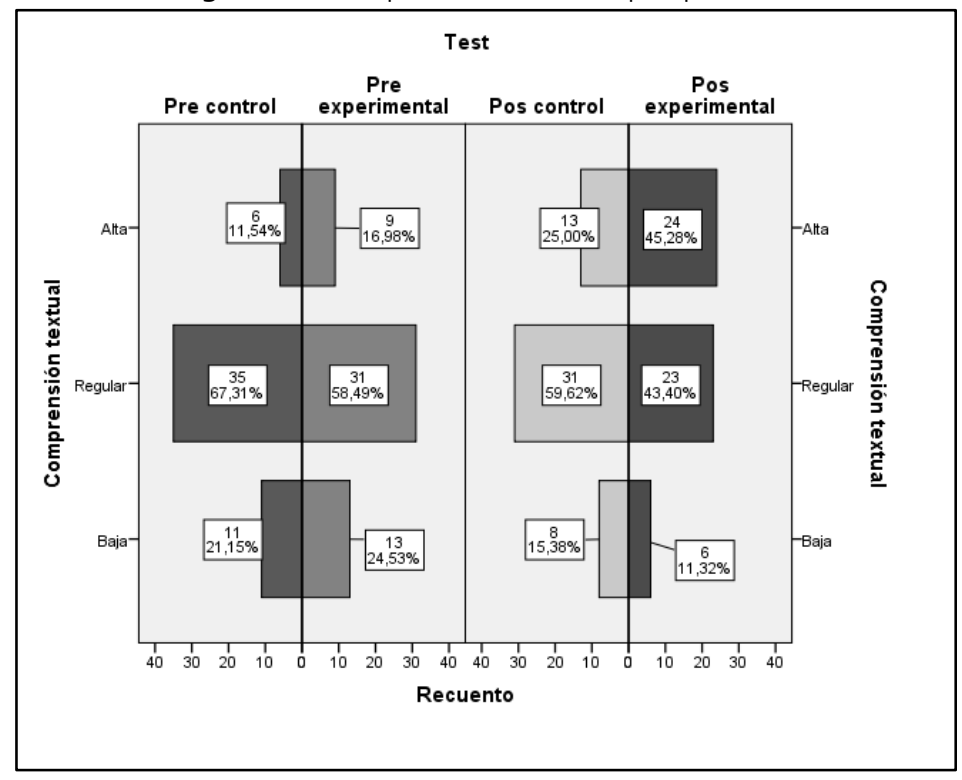




\subsection{Resultados inferenciales}

\section{Prueba de hipótesis general}

H0: Las estrategias metacognitivas en entornos digitales no mejoran la comprensión lectora.

Hi: Las estrategias metacognitivas en entornos digitales mejoran la comprensión lectora.

Tabla 2. Contrastación de la hipótesis general

\begin{tabular}{|c|c|c|c|c|}
\hline & \multicolumn{4}{|c|}{ Rangos } \\
\hline & Test & $\mathrm{N}$ & $\begin{array}{c}\text { Rango } \\
\text { promedio }\end{array}$ & $\begin{array}{c}\text { Suma } \\
\text { de rangos }\end{array}$ \\
\hline \multirow[t]{3}{*}{ Comprensión textual } & Pre control & 52 & 52.65 & 2738.00 \\
\hline & Pre experimental & 53 & 53.34 & 2827.00 \\
\hline & Total & 105 & & \\
\hline \multirow[t]{3}{*}{ Comprensión inferencial } & Pre control & 52 & 54.38 & 2828.00 \\
\hline & Pre experimental & 53 & 51.64 & 2737.00 \\
\hline & Total & 105 & & \\
\hline \multirow[t]{3}{*}{ Comprensión criterial } & Pre control & 52 & 53.19 & 2766.00 \\
\hline & Pre experimental & 53 & 52.81 & 2799.00 \\
\hline & Total & 105 & & \\
\hline \multirow[t]{4}{*}{ Comprensión lectora } & Pre control & 52 & 52.69 & 2740.00 \\
\hline & $\begin{array}{l}\text { Pre experimental } \\
\text { Total }\end{array}$ & $\begin{array}{c}53 \\
105\end{array}$ & 53.30 & 2825.00 \\
\hline & \multicolumn{4}{|c|}{ Estadísticos de pretest } \\
\hline & $\begin{array}{c}\text { Comprensión } \\
\text { textual }\end{array}$ & $\begin{array}{c}\text { Comprensión } \\
\text { inferencial }\end{array}$ & $\begin{array}{c}\text { Comprensión } \\
\text { criterial }\end{array}$ & $\begin{array}{c}\text { Comprensión } \\
\text { lectora }\end{array}$ \\
\hline U de Mann-Whitney & 1360.000 & 1306.000 & 1368.000 & 1362.000 \\
\hline W de Wilcoxon & 2738.000 & 2737.000 & 2799.000 & 2740.000 \\
\hline Z & -.134 & -.537 & -.074 & -.117 \\
\hline Sig. asintótica (bilateral) & .893 & .591 & .941 & .907 \\
\hline
\end{tabular}

Se observa en la Tabla 2 que en el pretest de Comprensión de textos narrativos los rangos del Grupo de Control y el Grupo Experimental no son tan diferenciados. Y que tanto el valor $p$ de significancia (mayor que $a=.05$ ) y el valor $Z$ (mayor que el límite crítico -1.96) corroboran que no existen diferencias significativas entre ambos grupos. Sin embargo, en el postest sí hay diferencia marcada en los rangos. Además, se aprecia que el $p$ de significancia (mayor que $a=.05$ ) y el valor $Z$ (menor que el límite crítico 1.96) corroboran que existen diferencias significativas entre ambos grupos. Por tanto, se rechaza la hipótesis nula y se concluye que las estrategias metacognitivas en entornos digitales mejoran significativamente la comprensión de textos narrativos.

\section{Prueba de hipótesis específica}

H0: Las estrategias metacognitivas en entornos digitales no mejoran la comprensión textual, inferencial y criterial.

Hi: Las estrategias metacognitivas en entornos digitales mejoran la comprensión textual, inferencial y criterial. 
Tabla 3. Contrastación de la hipótesis específica

\begin{tabular}{|c|c|c|c|c|}
\hline \multirow{5}{*}{ Comprensión textual } & \multicolumn{4}{|c|}{ Rangos } \\
\hline & Test & $\mathrm{N}$ & $\begin{array}{c}\text { Rango } \\
\text { promedio }\end{array}$ & $\begin{array}{c}\text { Suma } \\
\text { de rangos }\end{array}$ \\
\hline & Pre control & 52 & 47.64 & 2477.50 \\
\hline & Pre experimental & 53 & 58.25 & 3087.50 \\
\hline & Total & 105 & & \\
\hline \multirow[t]{2}{*}{ Comprensión inferencial } & Pre control & 52 & 46.77 & 2432.00 \\
\hline & $\begin{array}{l}\text { Pre experimental } \\
\text { Total }\end{array}$ & $\begin{array}{c}53 \\
105\end{array}$ & 59.11 & 3133.00 \\
\hline \multirow[t]{2}{*}{ Comprensión criterial } & Pre control & 52 & 46.00 & 2392.00 \\
\hline & $\begin{array}{l}\text { Pre experimental } \\
\text { Total }\end{array}$ & $\begin{array}{c}53 \\
105\end{array}$ & 59.87 & 3173.00 \\
\hline \multirow{4}{*}{ Comprensión lectora } & Pre control & 52 & 48.01 & 2496.50 \\
\hline & $\begin{array}{l}\text { Pre experimental } \\
\text { Total }\end{array}$ & $\begin{array}{c}53 \\
105 \\
\end{array}$ & 57.90 & 3068.50 \\
\hline & \multicolumn{4}{|c|}{ Estadísticos de pretest } \\
\hline & $\begin{array}{c}\text { Comprensión } \\
\text { textual }\end{array}$ & $\begin{array}{c}\text { Comprensión } \\
\text { inferencial }\end{array}$ & $\begin{array}{c}\text { Comprensión } \\
\text { criterial }\end{array}$ & $\begin{array}{c}\text { Comprensión } \\
\text { lectora }\end{array}$ \\
\hline U de Mann-Whitney & 1099.500 & 1054.000 & 1014.000 & 1118.500 \\
\hline W de Wilcoxon & 2477.500 & 2432.000 & 2392.000 & 2496.500 \\
\hline & -1.974 & -2.296 & -2.603 & -1.844 \\
\hline Sig. asintótica (bilateral) & .048 & .022 & .009 & .065 \\
\hline
\end{tabular}

Se observa en la Tabla 3 que en el pretest de Comprensión textual, Comprensión inferencial y Comprensión criterial de textos narrativos los rangos del Grupo de Control y el Grupo Experimental no son tan diferenciados. Y que tanto el valor $p$ de significancia (mayor que $a=.05$ ) y el valor $Z$ (mayor que el límite crítico -1.96) corroboran que no existen diferencias significativas entre ambos grupos. Sin embargo, en el postest sí hay diferencia marcada en los rangos de Comprensión textual y Comprensión criterial de textos narrativos. Además, se aprecia que el $p$ de significancia (menor que $a=.05$ ) y el valor $Z$ (menor que el límite crítico -1.96) corroboran que existen diferencias significativas entre ambos grupos. A excepción de la Comprensión inferencial que mantuvo tanto sus rangos similares y que tanto su valor $p$ de significancia y valor $Z$ se mantuvieron también altos, por ello la influencia en esta dimensión no es significativa. Por todo lo explicado, se rechaza de manera parcial la hipótesis nula y se concluye que las estrategias metacognitivas en entornos digitales mejoran significativamente la Comprensión textual y Comprensión criterial de textos narrativos.

\section{Discusión y conclusiones}

En la presente investigación se desarrollaron algunas actividades en entornos digitales con el objetivo de que los alumnos lean y comprendan textos narrativos cortos. La aplicación de este tipo de estrategia ha resultado de gran impacto. Estos resultados entran en dialógica controversia con lo hallado por Pulgar (2016), quien también empleó un diseño cuasiexperimental para corroborar la significatividad de la incorporación de herramientas TIC como estrategia para mejorar la comprensión de textos narrativos en estudiantes universitarios. Y concluyó que el efecto era de un $76.9 \%$ en la comprensión lectora general al término de su investigación. La incidencia en comprensión literal fue de 12.8 al 56\%; 7.7 al 66 \% en la comprensión inferencial; y 23.1 al $41 \%$ en la comprensión criterial. Resultados significativamente más altos de los hallados en el presente trabajo, pero que estarían signados por cierto sesgo en la elección de textos que no son narrativos, sino expositivos; y que a su vez el nivel de dificultad de las lecturas es disímil en su complejidad (el autor escoge textos cortísimos o fragmentos, mientras que en esta investigación se eligieron cuentos complejos de Borges. Se toma en cuenta también la edad los participantes como eje diferenciador).

Otro referente inmediato es la investigación realizada por Novoa et al. (2018), quienes encuentran una influencia significativa empleando la versión en físico de la variante digital empleada en este trabajo: el MMA. En dicha investigación se logra una significatividad $(p=.000)$, comprobando la hipótesis de trabajo, 
de que los MMA influyen significativamente en la comprensión de textos narrativos.

La importancia de añadir a las estrategias pedagógicas elementos digitales, como el caso de Vera (2015), quien realizó una investigación cuasiexperimental para comprobar los efectos de la multimodalidad en la comprensión de textos narrativos en estudiantes universitarios, entra en convergencia con lo hallado en esta investigación. El autor demostró que el grupo experimental sacó un puntaje escalar de 55.6 y el grupo control de 38.8 en comprensión general. Esta ventaja fue verificada por la prueba $t$ de Student $(t=6.381)$ y una significancia $p=0.000$. Aceptando con esto su hipótesis de trabajo al igual que en esta investigación. Aunque hay que anotar que el texto era en inglés y orientado a una segunda lengua.

Con relación a la lectura y comprensión en entornos digitales, este estudio encontró mejores resultados en el grupo experimental que tuvo una permanente actividad en dichos entornos. Estos hallazgos complementan los resultados de Rodríguez y Huertas (2017), quienes encontraron ligeras ventajas en la interpretación de textos narrativos de los participantes que emplearon cuadernos digitales con los que emplearon entornos tradicionales.

Esta investigación brinda la posibilidad de realizar un conjunto de estrategias combinadas tanto antes y después de la lectura de un texto narrativo y mejorar los resultados de su comprensión. Estas estrategias por lo general son dinámicas, flexibles y, sobre todo, activas. Y constituyen una vertiente aún no estudiada a profundidad sobre la comprensión de textos narrativos mediados por estrategias digitales en el ámbito escolar.

Se comprobó que una estrategia digital basada en la utilización de programas y aplicaciones virtuales de manera transversal (entre dos a cuatro días) tiene un efecto significativo en la comprensión de textos narrativos. Siempre y cuando se aprovechen los recursos digitales -como el diseño de organizadores visuales de alto impacto cognitivo como lo son los MMA.

Se evidenció que hubo mejora en las dimensiones de comprensión textual y comprensión criterial, pero no se consiguió la significancia en la comprensión inferencial, muy probablemente por el hecho de que exista un apresuramiento en las deducciones de los participantes. Una alternativa de solución es abordar ejercicios de Crucigrama y Sopa de letras con mayor asiduidad, ya que este tipo de ejercicios obligan a meditar sobre palabras clave de la comprensión. Asimismo, se demostró que el uso de programas y aplicativos digitales de empleo intuitivo y de poca complejidad e intromisión en las actividades educativas, tienen buenos resultados tanto en su aplicabilidad como en los resultados que evidencian mejoría.

Una de las limitaciones de la investigación fue la imposibilidad de que los participantes emplearan teléfonos móviles en clase, debido a un fuerte prejuicio en contra de su uso por parte de los jóvenes; otra fue el recargo en las programaciones curriculares -que limitan experiencias educativas que necesitan por lo menos tres días consecutivos para su realización. Es importante resaltar que el tipo de estrategias metacognitivas realizadas en este trabajo puede replicarse para niveles superiores, pues no sólo en el nivel escolar se observa el problema de la comprensión lectora, sino también en estudiantes universitarios.

\section{Referencias}

Alcas, N., Alarcón, M., Alarcón, H., González, R. y Rodríguez, A. (2019). Estrategias metacognitivas y comprensión lectora en estudiantes universitarios. Apuntes Universitarios, 9(1), 36-45.

https://doi.org/10.17162/au.v1i1.348

Arellano, M. (2019). Un marco teórico para la investigación del andamiaje a la autorregulación del aprendizaje en entornos virtuales (Cap. Tesis de posdoctorado). Universidad Siglo 21.

https://21.academia.edu/MarcosRequena/Thesis-Chapters 
Ayala, M., Barón, O. y Romero, M. (2017). Estrategia pedagógica mediada por el uso de las TIC para el fortalecimiento de la comprensión lectora en estudiantes grado quinto de primaria de la Institución Educativa San Josemaría Escrivá de Balaguer sede Samaria (Trabajo de grado). Fundación Universitaria los Libertadores. http://hdl.handle.net/11371/1575

Bendassolli, P., Borges-Andrade, J. y Malvezzi, S. (2010). Paradigmas, eixos temáticos e tensões na PTO no Brasil. Estudos de Psicologia (Natal), 15(3), 281-289. https://doi.org/10.1590/S1413-294X2010000300008

Borja, W., Guarnieri, G. y Rodríguez, G. (2019). Análisis y evaluación de procesos de interactividad en entornos virtuales de aprendizaje. Trilogía Ciencia Tecnología Sociedad, 11(20), 63-99.

https://doi.org/10.22430/21457778.1213

Cabero, J., Piñero, R. y Reyes, M. (2018). Material educativo multimedia para el aumento de estrategias metacognitivas de comprensión lectora. Perfiles Educativos, 40(159), 144-159. https://bit.ly/2zOU34r

Cáceres, X., Loyola, J. y Villegas, F. (2018). Marco de evaluación de la competencia lectora de PISA 2018. http://umc.minedu.gob.pe/wp-content/uploads/2017/11/Marco-teorico-Pisa-2018.pdf

Cantillo, K., De la Hoz, Á. y Cerchiaro, E. (2014). Actividad metacognitiva en estudiantes universitarios: un estudio preliminar. Psicología desde el Caribe, 31(3), 455-474.

http://rcientificas.uninorte.edu.co/index.php/psicologia/article/view/5399

Carrillo, S., Tigre, F., Tubón, E. y Sánchez, D. (2019). Objetos Virtuales de Aprendizaje como estrategia didáctica de enseñanza aprendizaje en la educación superior tecnológica. Revista Científica de la Investigación y el Conocimiento, 3(1), 287-304.

https://doi.org/10.26820/recimundo/3.(1).enero.2018.287-304

Chipana, E. (2018). Relación entre estrategias metacognitivas y comprensión lectora en los estudiantes de cuarto grado de educación secundaria en la Institución Educativa Honorio Delgado Espinoza Arequipa 2017 (Tesis de especialidad). Universidad Nacional de San Agustín de Arequipa.

http://repositorio.unsa.edu.pe/handle/UNSA/7489

Correa, E., Forero, D. y Vergara, R. (2018). La predicción y verificación como estrategia metacognitiva para la enseñanza de la comprensión lectora en la Institución Educativa Antonio Nariño del corregimiento (Tesis de maestría). Universidad de la Salle. https://ciencia.lasalle.edu.co/maest docencia yopal/48/

Cubillos, G. (2019). Estrategias metacognitivas en ambientes virtuales de aprendizaje para el fortalecimiento de habilidades auditivas musicales (Tesis de maestría). Universidad Pedagógica Nacional.

http://hdl.handle.net/20.500.12209/10718

Flavell, J. (1976). Metacognitive aspects of problem solving. In L. Resnick (Ed.). The Nature of intelligence (pp. 231-235). Lawrence ErlbaumAssociates.

Flavell, J. (1979). Metacognition and cognitive monitoring: A new area of cognitive-developmental inquiry. American psychologist, 34(10), 906. https://doi.orq/10.1037/0003-066X.34.10.906

Fonseca, L., Migliardo, G., Simian, M., Olmos, R., y León, J. A. (2019). Estrategias para Mejorar la Comprensión Lectora: Impacto de un Programa de Intervención en Español. Educational Psychology, 25(2), 91-99. https://doi.org/10.5093/psed2019a1

Fonseca, M.P., Pérez, J., Silva, H. y Gutiérrez-Ríos, M. (2018). S1103 Leer con propósito en aulas multigrado, desafíos y bienvenida a las comunidades de lectura. Tecné Episteme y Didaxis, (extraordinario), 1-14. https://revistas.pedagogica.edu.co/index.php/TED/article/view/8971 
González, M. N. (2018). Estrategias pedagógicas de aula como proyecto piloto de la Secretaria de Educación de Bogotá para abordar el problema de bajo nivel de comprensión lectora en los colegios oficiales. In Crescendo, 9(4), 611-628. https://revistas.uladech.edu.pe/index.php/increscendo/article/view/2071/0

González-López, M. G. (2019). La enseñanza de habilidades de pensamiento y de la comprensión lectora en estudiantes de bajo rendimiento escolar. Areté: Revista Digital del Doctorado en Educación de la Universidad Central de Venezuela, 5(9), 145-167. http://saber.ucv.ve/ojs/index.php/rev arete/article/view/16284

Gracida, J. (2012). La competencia lectora desde PISA: Los textos continuos, ¿cómo se leen? México. INEE. https://www.inee.edu.mx/wp-content/uploads/2018/12/Textos continuos.pdf

Graham, S., Harris, K. y Mason, L. (2005). Improving the writing performance, knowledge, and self-efficacy of struggling young writers: The effects of self-regulated strategy development [Mejora del rendimiento de la escritura, el conocimiento y la autoeficacia de los escritores jóvenes con dificultades: los efectos del desarrollo de estrategias autorreguladas]. Contemporary Educational Psychology, 30(2), 207-241.

https://doi.org/10.1016/i.cedpsych.2004.08.001

Grimaldo, M. (1998). Niveles de comprensión lectora en estudiantes de quinto año de educación secundaria de nivel socioeconómico medio y bajo. Liberabit, 4(4), 19-26.

http://revistaliberabit.com/es/revistas/RLE 041 niveles-de-comprension-lectora-en-estudiantes-dequinto-ano-de-educacion-secundaria-de-nivel-socioeconomico-medio-y-bajo.pdf

Hechavarría, Y. Y., González, V. M. y López T. P. (2019). Entornos virtuales de aprendizaje como medio facilitador para integrar tecnologías al currículo de la educación primaria. Tecnología Educativa, 4(1), 64-71. https://tecedu.uho.edu.cu/index.php/tecedu/article/view/112

Jacobs, J. E. y Paris, S. G. (1987). Children's metacognition about reading: Issues in definition, measurement, and instruction. Educational psychologist, 22(3-4), 255-278.

https://doi.org/10.1080/00461520.1987.9653052

Klimovsky, G. (1971). El método hipotético deductivo y la lógica. UNLP. FAHCE. Instituto de Lógica y Filosofía de las Ciencias. http://www.memoria.fahce.unlp.edu.ar/libros/pm.177/pm.177.pdf

Lozano, Y. (2018). Desarrollo de habilidades metacognitivas para fortalecer la comprensión lectora a través de un ambiente de aprendizaje en niños de tercer grado apoyado por TIC (Tesis de maestría). Universidad de La Sabana. https://intellectum.unisabana.edu.co/handle/10818/34601

Malhotra, N. (2008). Investigación de Mercados (5a. ed.). Pearson Educación de México.

Martínez, L., Hamon, W. y Mendoza, C. (2018). Implementación de estrategias pedagógicas y didácticas para mejorar la comprensión lectora y escritora mediante el uso de herramientas tecnológicas, en los estudiantes del Grado Quinto de La Institución Educativa Henry Daniels del Municipio de Castilla La Nueva (Meta). (Trabajo de grado). Universidad Nacional Abierta y a Distancia-UNAD.

https://repository.unad.edu.co/handle/10596/18790

Martínez, M. Á. y Caballero, R. (2019). Los Mapas Mentales como Estrategia Metacognitiva para mejorar la Comprensión de lectura en textos narrativos: las Leyendas Colombianas (Tesis de grado). Universidad libre. https://repository.unilibre.edu.co/handle/10901/15687

Martínez, M., Marrujo, J., Perillo, M., González, F. y Burin, D. (2019). Comprensión de texto en E-learning: estrategias de soporte y memoria de trabajo. Ocnos: Revista de estudios sobre lectura, 18(2), 31-43.

https://doi.org/10.18239/ocnos 2019.18.2.1988 
Meana, E. (2018). Lectura y escritura académicas en entornos digitales. Obstáculos epistemológicos. Extensionismo, Innovación y Transferencia Tecnológica, (4), 129-135.

http://dx.doi.org/10.30972/eitt.402881

Mengual, E. (2017). Metacomprensión e inteligencia emocional: relación e influencia en la comprensión lectora en alumnado de 5o. y 6o. de educación primaria (Tesis Doctoral), Universidad Complutense de Madrid. https://eprints.ucm.es/43467/

Ministerio de Educación. (2018). Marco de evaluación de la competencia lectora de PISA 2018. http://umc.minedu.gob.pe/wp-content/uploads/2017/11/Marco-teorico-Pisa-2018.pdf

Mogrovejo, V. (2019). Estrategias metacognitivas y su relación con los niveles de comprensión lectora de textos expositivos en los estudiantes del primer ciclo en el Instituto Pedagógico María Montessori, Arequipa-2018 (Tesis de maestría). Universidad Nacional de San Agustín de Arequipa.

http://repositorio.unsa.edu.pe/handle/UNSA/7984

Morado, M. F. y Ocampo, S. (2019). Una experiencia de acompañamiento tecno-pedagógico para la construcción de Entornos Virtuales de Aprendizaje en Educación Superior. Revista Educación, 43(1), 22152644. https://doi.org/10.15517/revedu.v43i1.28457

Morales, F. (18 de mayo de 2010). Tipos de investigación científica. Antropología para todos. https://antropologiaparatodos.wordpress.com/2014/10/02/tips-de-investigacion/

Morales, S. (2011). Variables socioculturales y cognitivas en el desarrollo de la comprensión de lectura en Lima, Perú. Revista Peruana de Investigación Educativa, (3), 96-129.

https://revistas.siep.org.pe/index.php/RPIE/article/view/18

Morles, A. (1991). El desarrollo de las habilidades para comprender la lectura y la acción docente. En A. Puente, Comprensión de la lectura y acción docente (261-274). Fundación Germán Sánchez Ruipérez. Pirámide.

Mujica, A., Guido, P. y Mercado, S. (2011). Actitudes y comportamiento lector: una aplicación de la teoría de la conducta planeada en estudiantes de nivel medio superior. Liberabit, 17(1), 77-84. http://revistaliberabit.com/en/revistas/RLI 171 attitudes-and-reader-behavior-an-application-of-thetheory-of-planned-behavior-of-students-in-upper-intermediate-level.pdf

Noriega, E. (2018). Estrategia Metacognitiva para mejorar los niveles de Comprensión Lectora en los Niños y Niñas del $2^{\circ}$ Grado de Educación primaria de la Institución Educativa Nº14 "Miguel Grau", Villa puerto Pizarro, Provincia Tumbes, 2014 (Tesis de maestría). Universidad Nacional "Pedro Ruiz Gallo" de Lambayeque. http://repositorio.unprg.edu.pe/handle/UNPRG/6530

Novoa, P., Cancino, F., Flores, S. y Nieto, J. (2018). El mapa mental armónico en la comprensión de textos narrativos en estudiantes universitarios. Propósitos y representaciones, 6(2), 541-573.

http://dx.doi.org/10.20511/pyг2018.v6n2.243

Patiño, S. (2018). Estrategias metacognitivas para desarrollar la comprensión lectora en los estudiantes de las Escuelas de Educación Básica Media, Parroquia de Conocoto, Distrito Nueve, Zona Ocho (Tesis de maestría) Universidad Central del Ecuador. http://www.dspace.uce.edu.ec/handle/25000/16260

PISA (2018). Assessment and Analytical Framework. OECD Publishing. Organisation de coopération et de développement économiques. http://www.oecd.org/education/pisa-2018-assessment-and-analyticalframework-b25efab8-en.htm

Puente, A., Jiménez, V. y Alvarado, J. M. (2009). Escola: Escala de conciencia lectora. Ciencias Psicológicas, 3(2), 249-250. https://doi.org/10.22235/cp.v3i2.157 
Pulgar, M.P. (2016). Incorporación de las herramientas tics para incrementar la comprensión lectora de textos narrativos en los estudiantes de primer ciclo de la facultad de derecho de una universidad privada de Lima (Tesis de maestría). Universidad Peruana Cayetano Heredia.

http://190.116.48.43/handle/upch/646

Rodríguez, A. y Huertas, A. (2017). Diferenciación de la interpretación de textos narrativos en la modalidad cuadernos digitales vs. ambientes tradicionales. Experiencias Investigativas y Significativas, 3(3), 195-206. https://experiencias.iejuliussieber.edu.co/index.php/Exp-inv/article/view/23

Rosales, R. (2018). Relación entre estrategias de aprendizaje y nivel de comprensión lectora de los estudiantes del segundo grado de educación secundaria de la institución educativa Pedro Pablo AtuspariaHuaraz-2018 (Tesis de grado). Universidad Nacional "Santiago Antúnez de Mayolo".

http://repositorio.unasam.edu.pe/handle/UNASAM/3390

Rueda, L. y Gutiérrez, Y. (2019). Efecto de la estrategia metacognitiva TWA (thinkbeforereading, thinkwhilereading, thinkafterreading) en el fortalecimiento de la lectura crítica (Tesis doctoral). Universidad de la Costa. http://hdl.handle.net/11323/5222

Solé, I. (2005). Estrategias de lectura. Graó.

Tapia, S. (2019). Estrategias metodológicas en la comprensión lectora (Tesis de grado). Universidad de Guayaquil.

Tapia-Repetto, G., Gutierrez, C. y Tremillo-Maldonado, O. (2019). Nuevas tecnologías en educación superior. Estudio de percepción en estudiantes acerca del uso de WhatsApp y Entornos Virtuales de Aprendizaje (Plataforma Moodle). Odontoestomatología, 21(33), 37-43.

http://dx.doi.org/10.22592/ode2019n33a5

Vega, B. (2019). Entornos virtuales de aprendizaje y habilidades metacognitivas en los estudiantes de la Facultad de Ciencias Contables de la Universidad Nacional Mayor de San Marcos (Tesis de maestría). Universidad Nacional de Educación Enrique Guzmán y Valle.

http://repositorio.une.edu.pe/handle/UNE/2944

Vega-Malagón, G., Ávila-Morales, J., Vega-Malagón, A., Camacho-Calderón, N., Becerril-Santos, A., y LeoAmador, G. (2014). Paradigmas en la investigación. Enfoque cuantitativo y cualitativo. European Scientific Journal, 10(15), 523-528. http://www.eujournal.org/index.php/esj/article/viewFile/3477/3240

Vera, F. (2015). Impacto de la multimodalidad en la comprensión lectora de textos narrativos en inglés como lengua extranjera (L2) en estudiantes universitarios. Contextos educativos: Revista de Educación, (18), 25-41. https://doi.org/10.18172/con.2608

Vílchez, M. (2003). Hábitos de lectura de los adolescentes peruanos: nuevas perspectivas. Revista Interamericana de Bibliotecología, 26(2), 57-71.

https://revistas.udea.edu.co/index.php/RIB/article/view/3069 


\section{Anexo 1}

MMA metacognitivos en entorno miMind (pre-llenados)

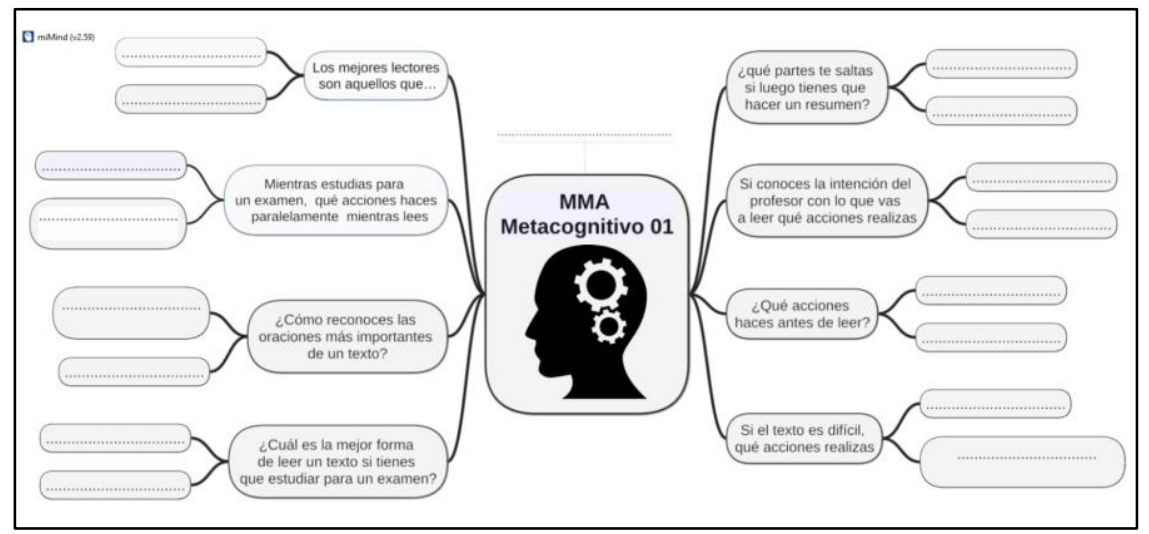

MMA Nro.001 prellenado

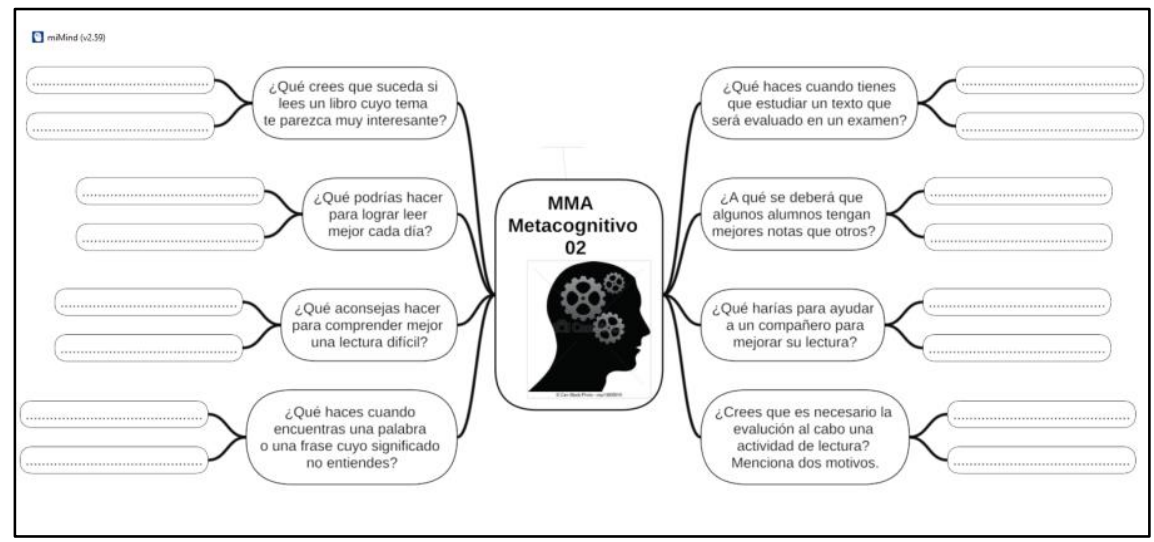

MMA Nro.003 prellenado

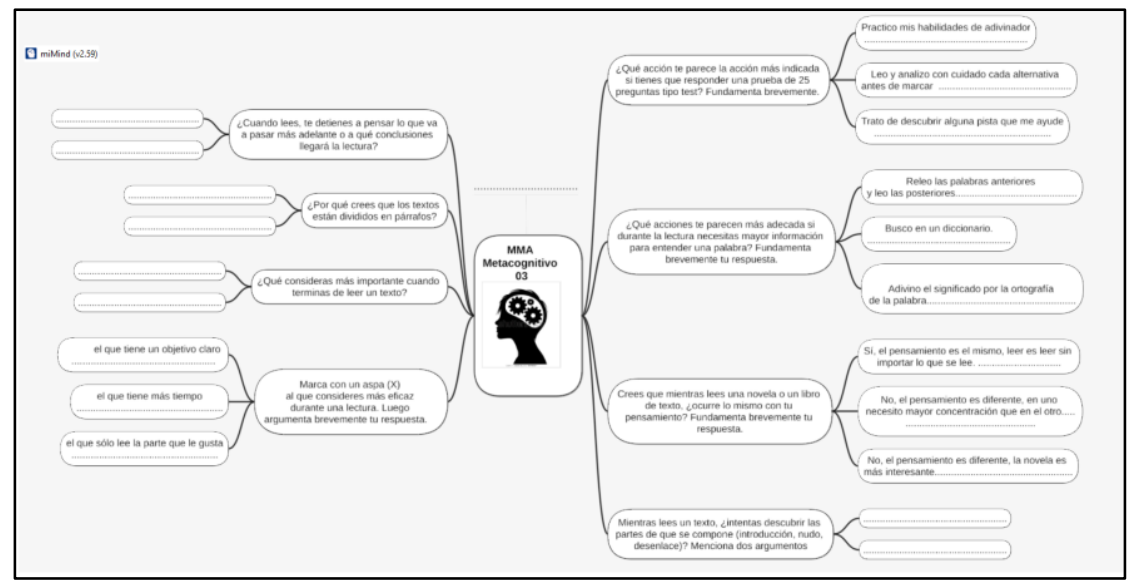




\section{MMA Nro.004 prellenado}

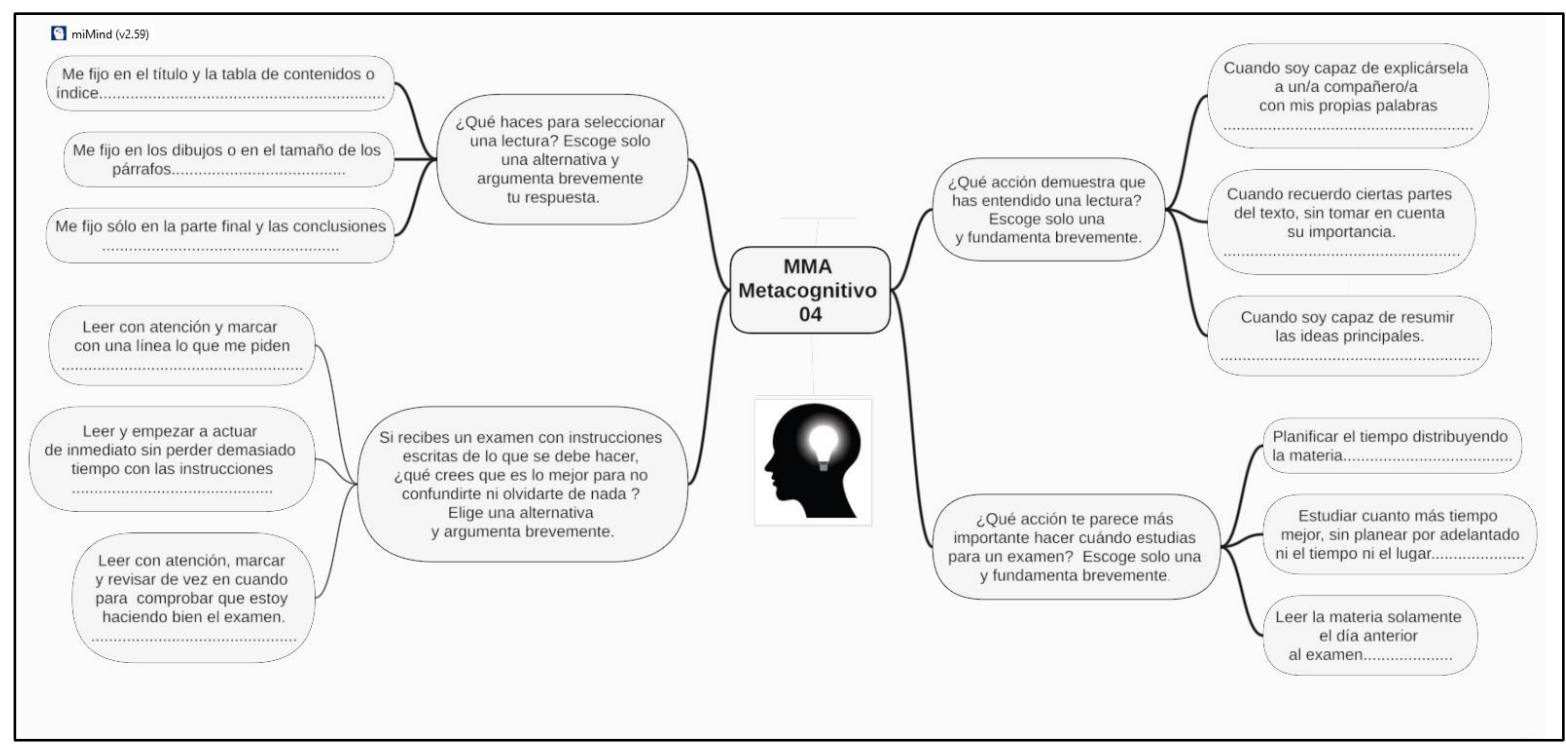




\section{Anexo 2}

\section{Crucigrama ${ }^{7}$ y sopa de letras ${ }^{8}$ en Educaplay basados en palabras clave del metacognición}

¡oucoplay Actividades $\vee$ Ej.: Partes de la célula...

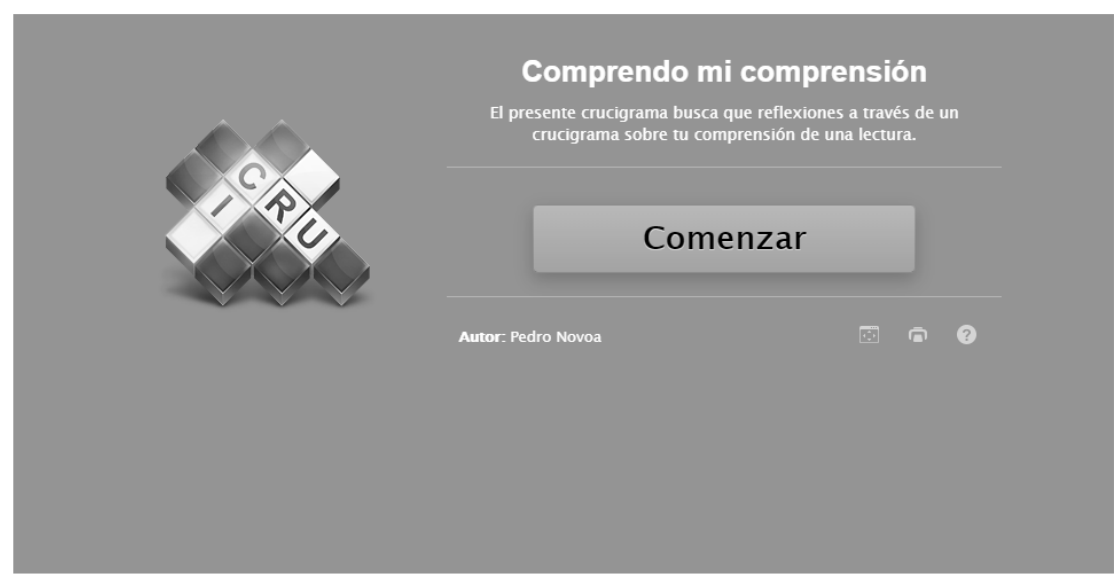

\section{educoplay Actividades $\vee \quad$ Ej.: La revolución francesa...}

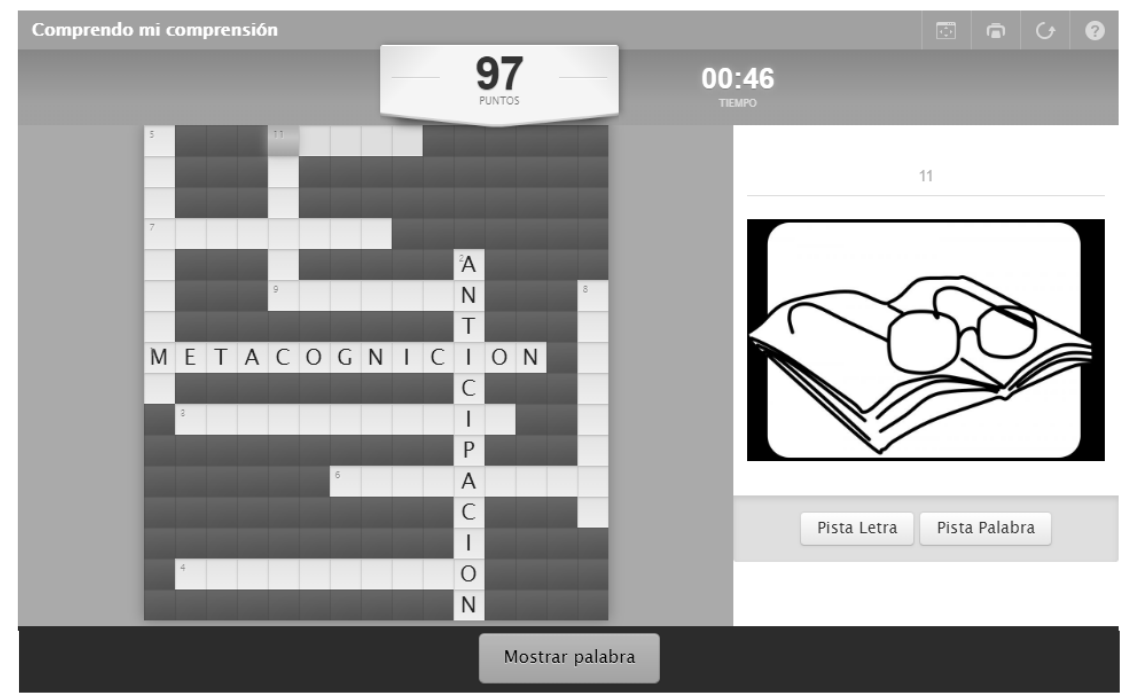

\footnotetext{
${ }^{7}$ Disponible en https://es.educaplay.com/recursos-educativos/6205911-comprendo mi comprension.html 8 Disponible en https://es.educaplay.com/recursos-educativos/6206513-mi comprension.html
} 

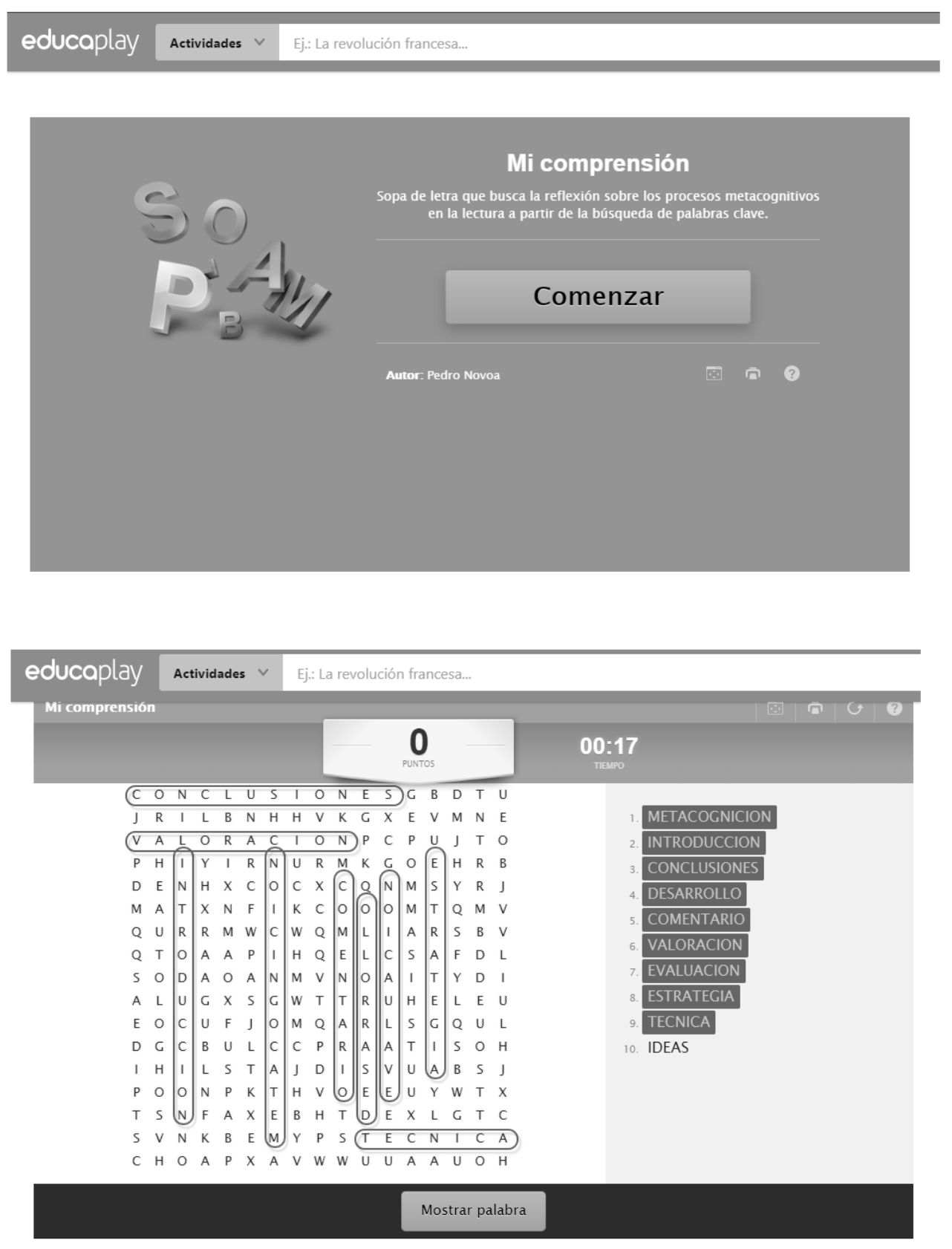


\section{Test ESCOLA en Google Form ${ }^{9}$}

$24 / 6 / 2020$

Test Escola (28-A)

\section{Test Escola (28-A)}

Puente, Jiménez y Alvarado; 2009

Antes de comenzar a leer, ¿qué haces para ayudarte durante la lectura

No hago ningún plan, simplemente empiezo a leer.

Tengo en cuenta la razón por la que voy a leer

Elijo un lugar confortable para leer.

Si tienes que estudiar un tema que desconoces completamente y el texto es dificil de leer, ¿Cómo podrias mejorar la capacidad de aprendizaje?

Ampliando los conocimientos por otros medios (profesor, enciclopedias, etc.)

Ampliando los conocimientos y desarrollando nuevas estrategias de lectura

Repitiendo las ideas del texto de forma mecánica, aunque nos las entienda

Una vez leido un texto, ¿qué partes te saltas si luego tienes que hacer un resumen?

Me salto aquellas partes cuyo significado no entiendo.

Me salto aquellas partes que no son importantes.

No me salto nada, pero leo con más atención aquello que me parece más importante.

${ }^{9}$ Disponible en https://docs.google.com/forms/d/e/1FAlpQLScPKcszJUo1KvMNny4Lx3w6fxRPsoWalGI1IVWvbuakyPFKg/viewform 


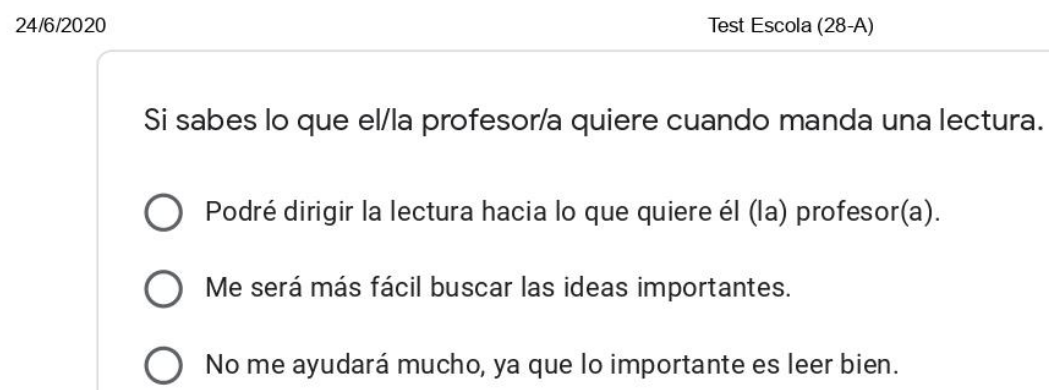

En la clase hay niños/as que leen bien y otros/as no tan bien. Tú crees que los/as mejores lectores/as son aquellos/as que...

Leen rápido pero no se dan cuenta de los errores.

Leen rápido, entonan bien y se dan cuenta de los errores

No me ayudará mucho, ya que lo importante es leer bien.

Si tienes que estudiar para un examen y el/la profesor/a te manda estudiar algunas lecciones. ¿Qué haces mientras las estudias?

Leo con la televisión y/o con la música puesta.

Nada especial, leo intentando comprender y recordar las ideas.

Imagino las preguntas que hará y leo las lecciones pensando en ellas.

¿Cómo podrías saber cuáles son las oraciones más importantes de un texto?

Reconociendo las oraciones que expresan las ideas principales.

Analizando las oraciones más largas.

Recordando los detalles que se describen

!

https://docs.google.com/forms/d/e/1FAlpQLScPKcszJUo1KvMNny4Lx3w6fxRPsoWalGI1IVWvbua-kyPfKg/viewform 


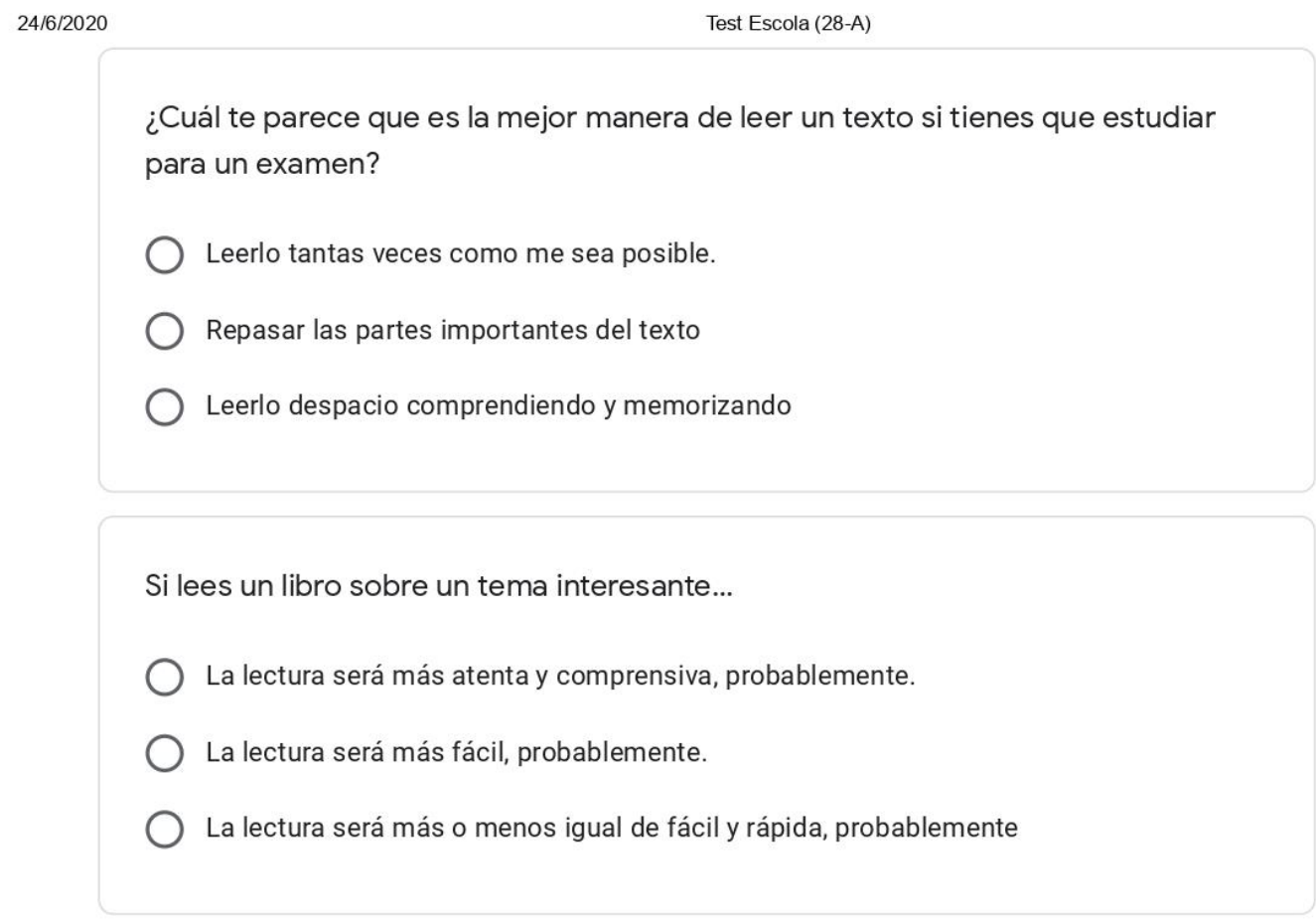

Para conseguir leer mejor cada día, ¿qué podrias hacer?

Leer libros con muchas ilustraciones

Leer más libros en mis ratos libres

Leer libros a otros y comentarlos con ellos

\section{Cuando tienes que leer un texto difícil, lo aconsejable es: \\ Leerlo más lentamente \\ Leerlo más veces \\ Leerlo lenta y comprensivamente.}




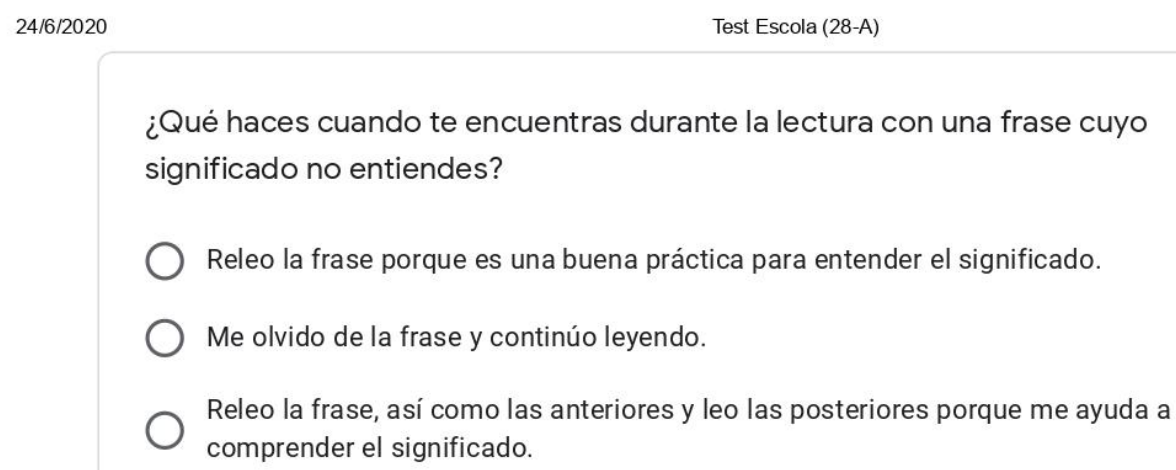

¿Qué haces cuando el/la profesor/a te manda estudiar un texto para después tomar un examen?

Dedico más atención y esfuerzo a las partes difíciles.

Leo de la misma forma las partes fáciles y difíciles.

Dedico más tiempo a lo difícil y hago resúmenes.

En la clase hay estudiantes que obtienen mejores notas que otros. Tú crees que las calificaciones que obtienen se deben a que...

Algunos/as estudiantes tienen más facilidad para estudiar y aprender porque leen mejor.

Todos/as saben leer, pero algunos/as estudian más.

Leer bien o mal no tiene mucha importancia.

Si tuvieras que ayudar a un/a compañero/a a mejorarla lectura, ¿qué harias?

Recomendarle que lea todos los días.

Leer con él/ella ayudándolo/a a comprender el texto.

Leer juntos y comentar lo leído. 
Al llevar a cabo una actividad de lectura:

Creo que es útil evaluar si he comprendido lo que estaba escrito.

Creo que la evaluación está bien, pero la tiene que hacer una persona mayor.

No creo que después de leer sea ya útil ninguna evaluación.

Mientras estás leyendo, ¿te detienes a pensar lo que va a pasar más adelante o a qué conclusiones llegará el/la autor/a?

No, porque me desconcentro.

Sí, porque me ayuda siempre a entender la lectura.

A veces, puesto que me ayuda a entender aspectos poco claros.

¿Por qué crees que los textos están divididos en párrafos?

Porque así lo exige la presentación del texto.

Porque en cada párrafo se expresa generalmente una idea separada relacionada con la anterior.

Porque facilita la comprensión del texto.

¿Qué consideras más importante cuando terminas de leer un texto?

Saber de qué trata el texto que he leído.

Recordar los detalles de los que trata el texto.

Poder resumir las ideas principales. 


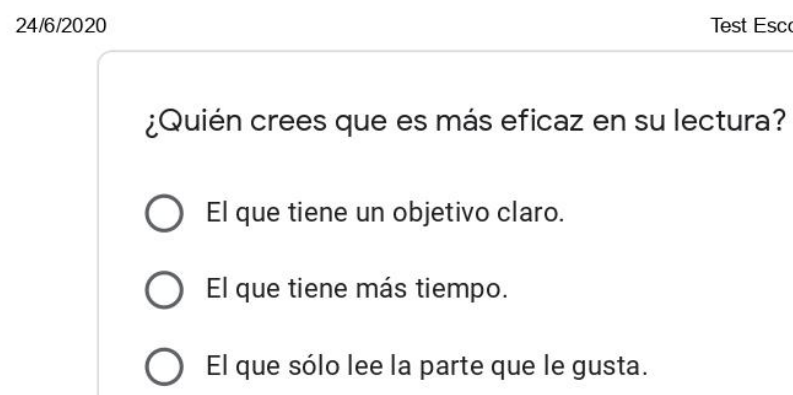

Si tienes que contestar un examen con 25 preguntas tipo test, ¿cómo lo realizas?

Practico mis habilidades de adivinador/a.

Leo y analizo con cuidado cada alternativa antes de marcar.

Trato de descubrir alguna pista que me ayude.

Si durante la lectura necesitas mayor información para entender una palabra, qué haces?

Releo las palabras anteriores y leo las posteriores.

Busco en un diccionario.

Adivino el significado por la ortografía de la palabra.

Crees que mientras lees una novela o un libro de texto, ¿ocurre lo mismo con tu pensamiento?

Sí, el pensamiento es el mismo, leer es leer sin importar lo que se lee.

No, el pensamiento es diferente, en uno necesito mayor concentración que en otro.

No, el pensamiento es diferente, la novela es más interesante. 


Mientras lees un texto, ¿intentas descubrir las partes de que se compone
(introducción, nudo, desenlace)?
Sí, ya que generalmente facilita la comprensión y el recuerdo del texto.
Sí, ya que los textos difíciles se comprenden mejor descubriendo los componentes.
No creo que sea muy importante para recordar las ideas.

Si recibes un examen con instrucciones escritas de lo que se debe hacer, ¿qué crees que es lo mejor para no confundirte ni olvidarte de nada en la realización del examen?

Leer con atención y marcar con una línea lo que me piden.

Leer y empezar a actuar de inmediato sin perder demasiado tiempo con las instrucciones

Leer con atención, marcar y revisar de vez en cuando para comprobar que estoy haciendo bien el examen.

¿Cómo sabes que has entendido una lectura?

Cuando soy capaz de explicársela a un/a compañero/a con mis propias palabras.

Cuando recuerdo ciertas partes del texto, sin tomar en cuenta su importancia.

Cuando soy capaz de resumir las ideas principales.
¿Cuándo estudias para un examen te parece importante...
Planificar el tiempo distribuyendo la materia.
Estudiar cuanto más tiempo mejor, sin planear por adelantado ni el tiempo ni el lugar.
Leer la materia solamente el día anterior al examen. 


¿Qué haces para seleccionar (28-A)
Me fijo en el título y la tabla de contenidos o índice.
Me fijo en los dibujos o tamaño de los párrafos
Me fijo sólo en la parte final y las conclusiones.

Enviar

Google no creó ni aprobó este contenido. Denunciar abuso - $\underline{\text { Condiciones del Servicio }- \text { Política de Privacidad }}$

\section{Google Formularios}




\section{Metacomprendo lo que leo 8}

En Vivo 昭

29 de enero de $2020,8: 47$ a.m.

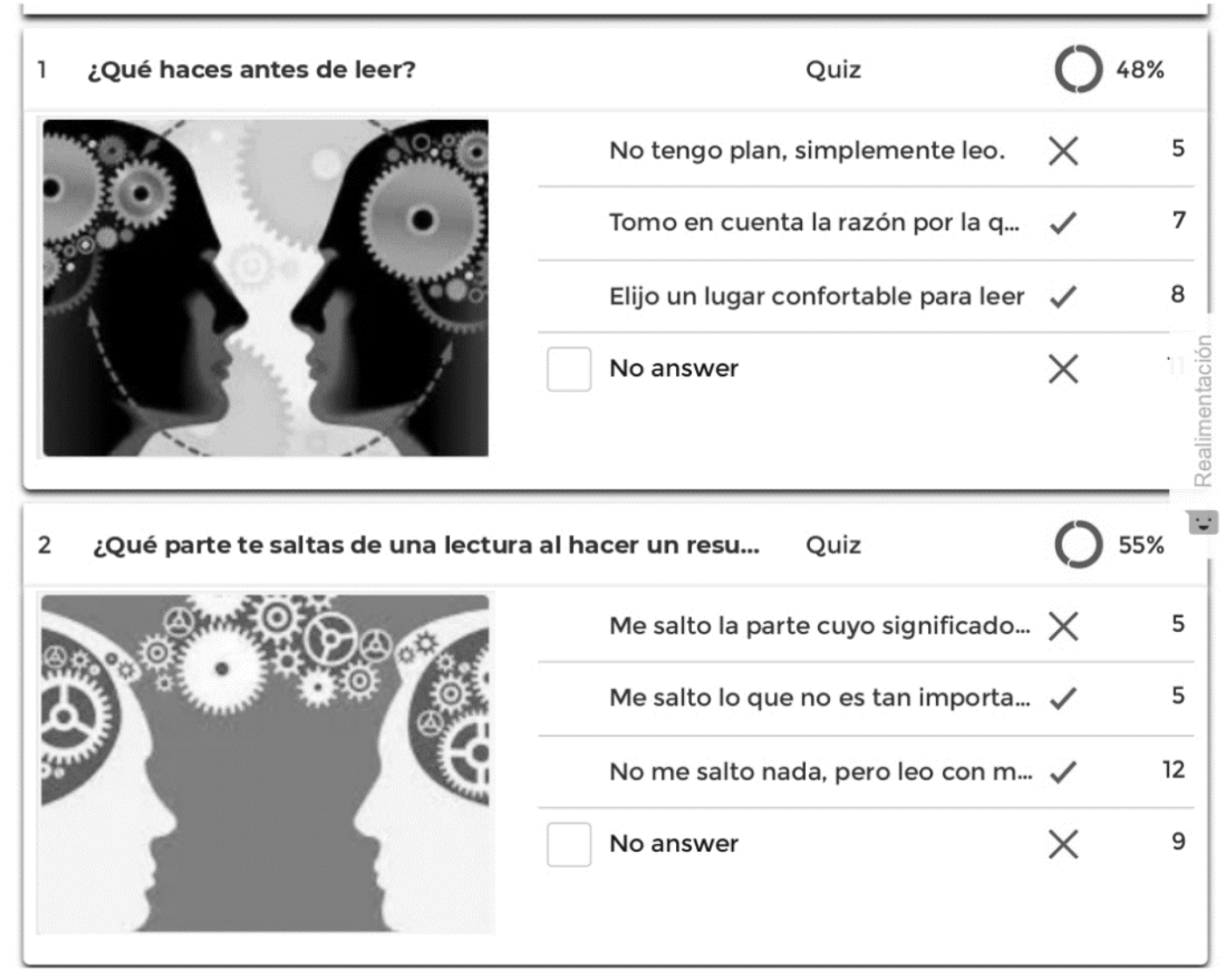

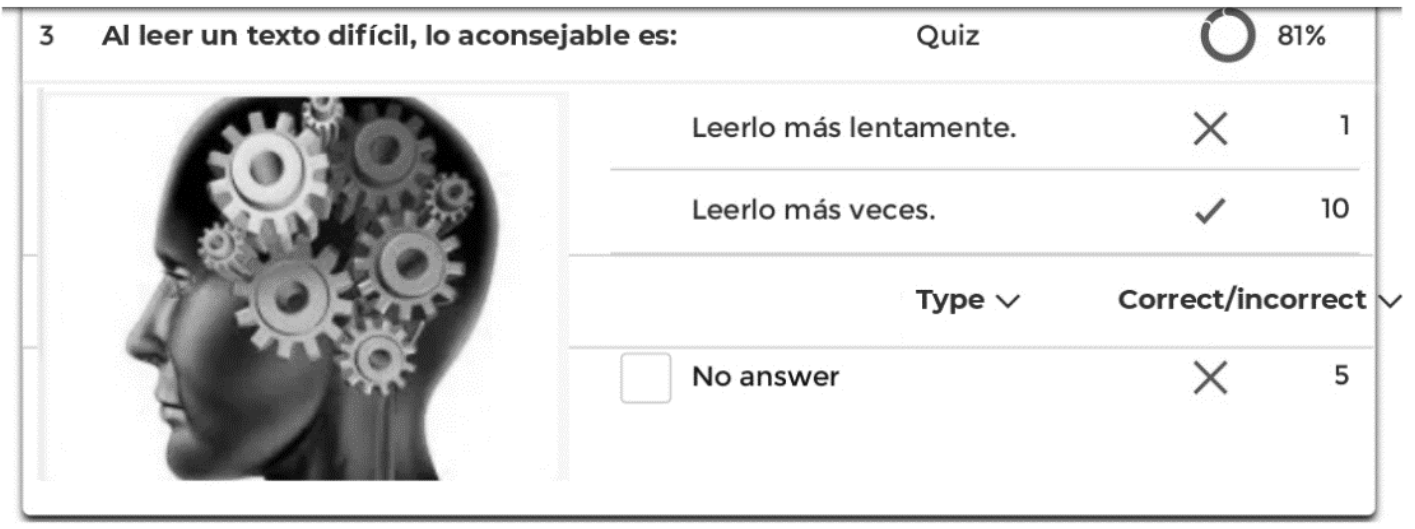

${ }^{10}$ Elace disponible hasta el 23 de julio del 2020 https://kahoot.it/challenge/03149546?challenge-id=280dcee8-c3ee4cbb-834e-0a36dabeb0ed 1593023127306 


\section{Metacomprendo lo que leo}

\section{En Vivo 咹}

29 de enero de 2020. 8:47 a.m.

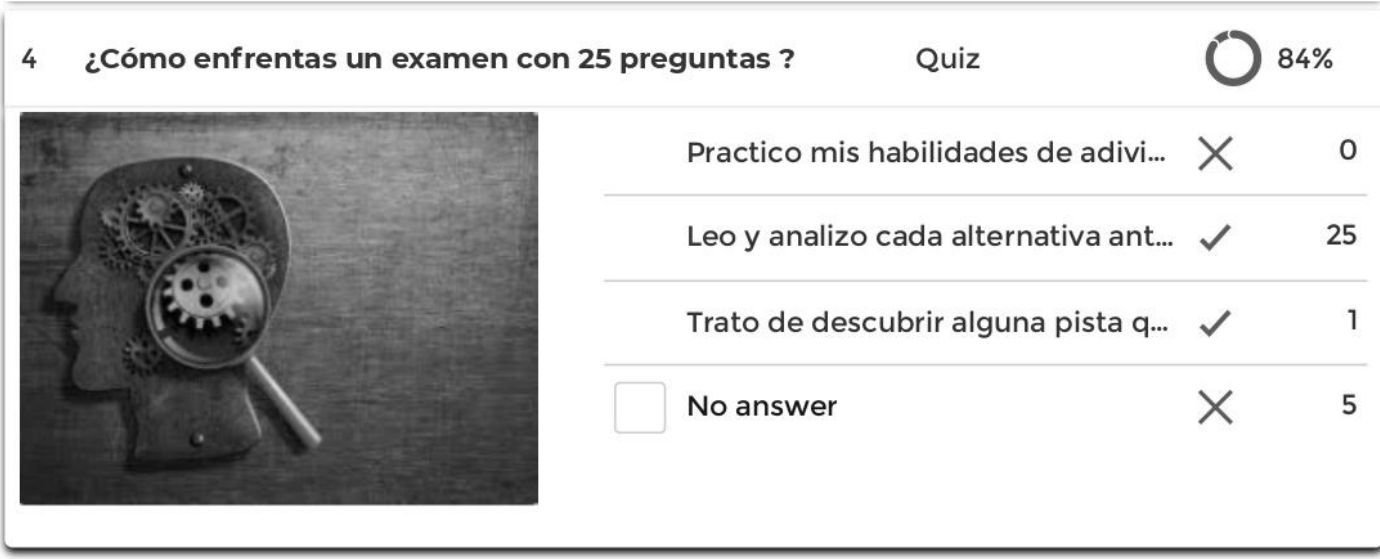

5 ¿Cómo identificas las oraciones más importantes de ... Quiz
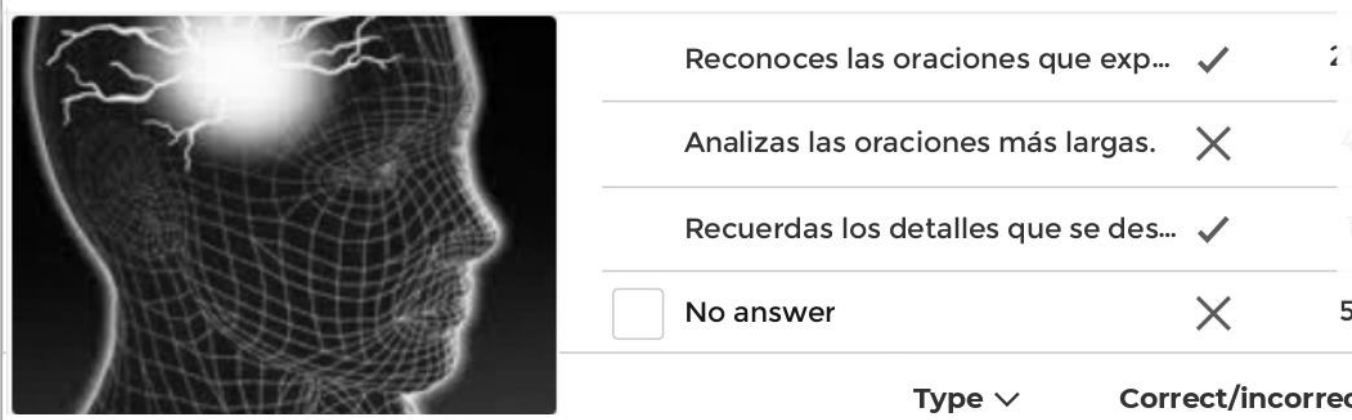

Analizas las oraciones más largas. X

Recuerdas los detalles que se des... $\checkmark$

No answer

$\times \quad 5$

Type $\vee$

Correct/incorrect $\checkmark$

6 ¿Qué le aconsejarías a un compañero para mejorar s... Quiz

Recomendarle que lea todos los ... X
Leer con él ayudándolo a compre...
No answer




\section{Anexo 3}

\section{MMA metacognitivos en entorno miMind (completados)}

\section{MMA Nro.001 completado}

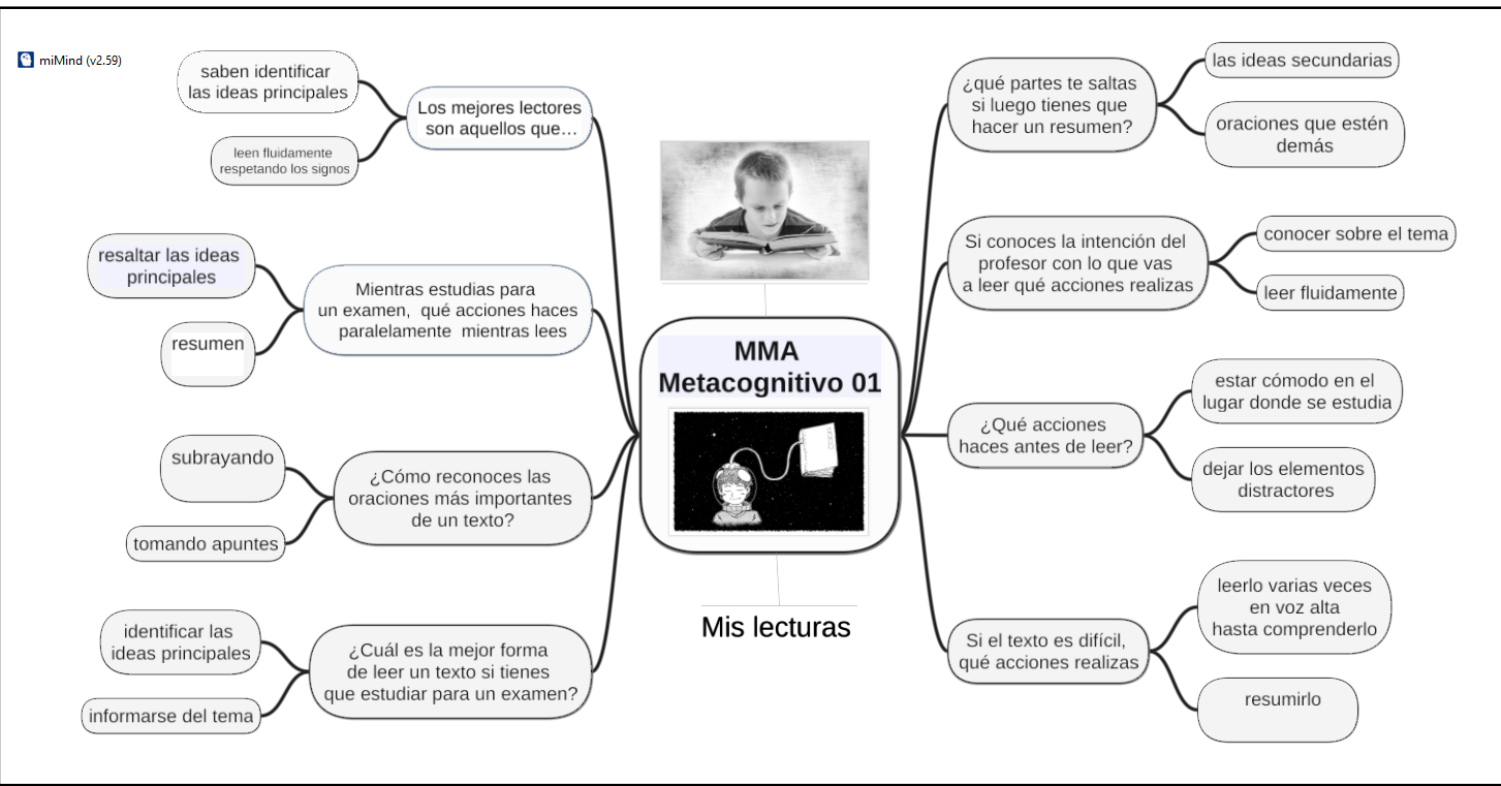

MMA Nro.002 completado

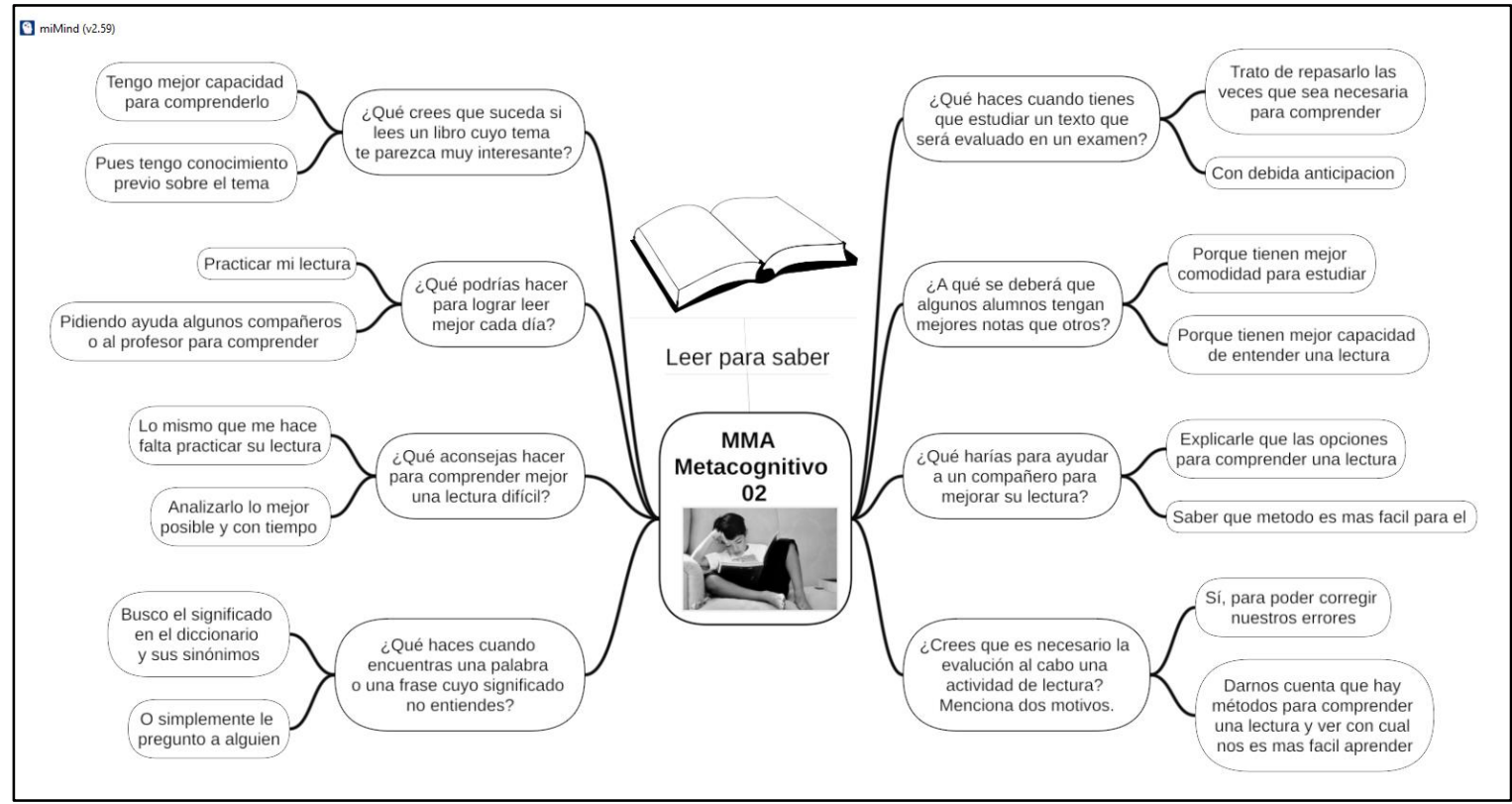




\section{MMA Nro.003 completado}

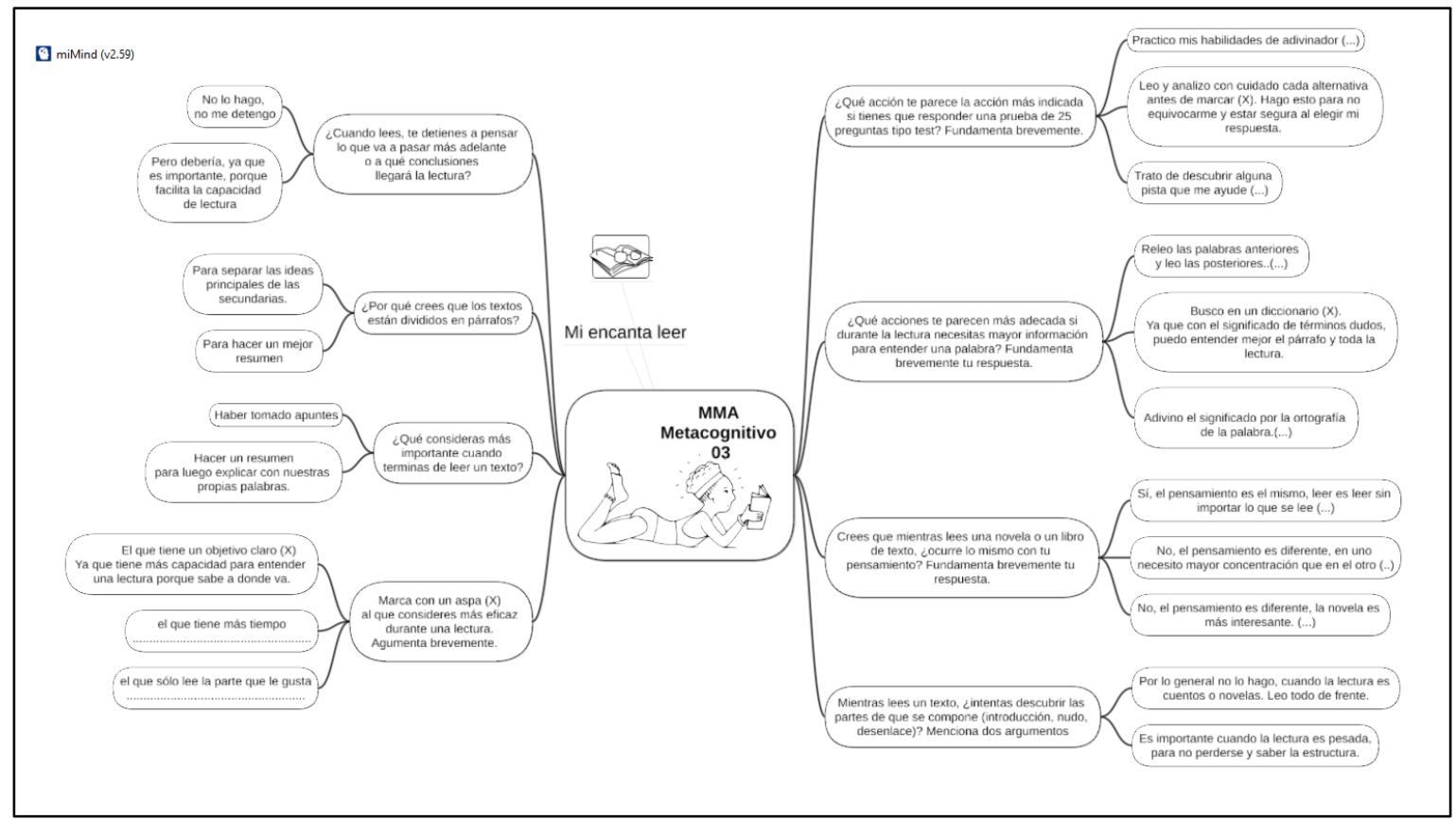

MMA Nro.004

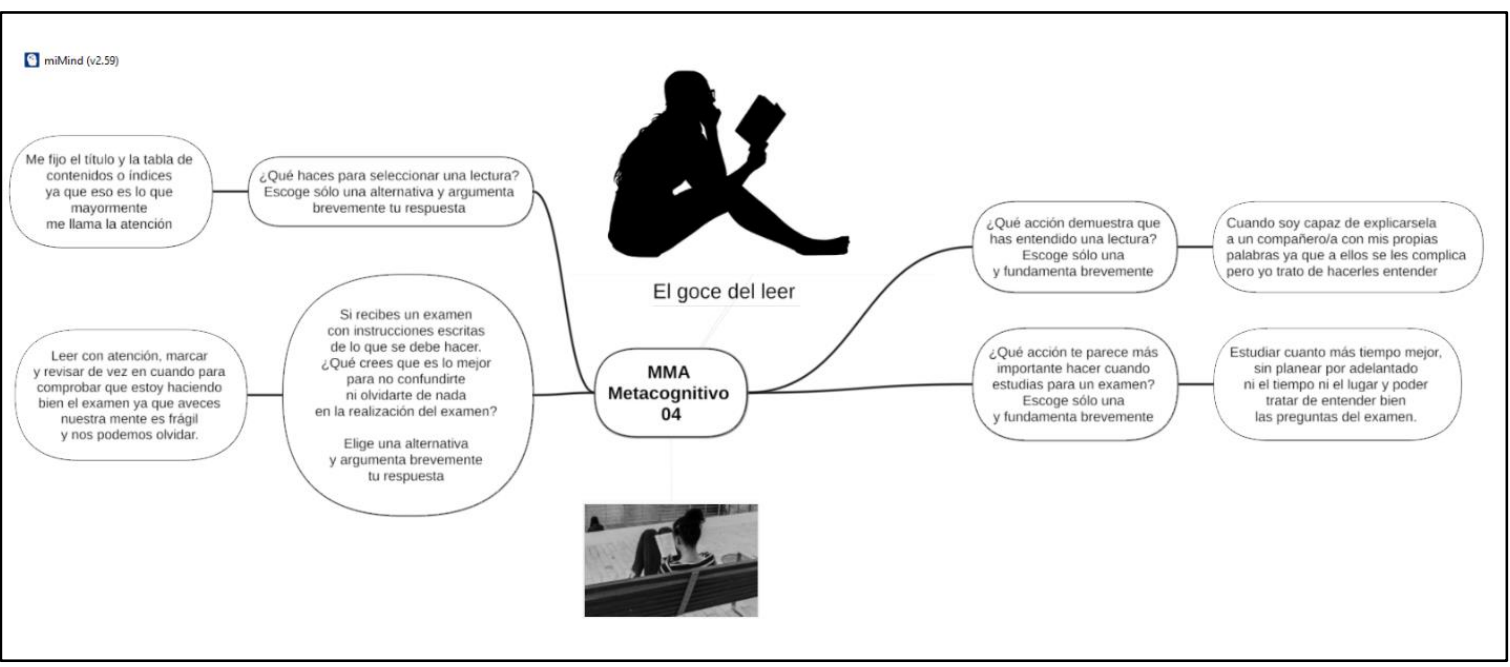

